\title{
IL4 Reduces Epileptogenesis Susceptibility Acutely After TBI: The Role of Macrophage/Microglia Polarization
}

Mozhdeh Radpour

Pasteur Institute of Iran

Bahar Khoshkroodian

Pasteur Institute of Iran

Tara Asgari

Pasteur Institute of Iran

Hamid Gholami Pourbadie

Pasteur Institute of Iran

Mohammad Sayyah ( $\nabla$ sayyahm2@pasteur.ac.ir)

Pasteur Institute of Iran https://orcid.org/0000-0003-0603-2444

\section{Research Article}

Keywords: Arginase-1, Kindling, Rat, Trauma, Traumatic epilepsy

Posted Date: November 16th, 2021

DOI: https://doi.org/10.21203/rs.3.rs-1068071/v1

License: (c) (1) This work is licensed under a Creative Commons Attribution 4.0 International License. Read Full License 


\section{Abstract}

Traumatic brain injury (TBI) is responsible for $5 \%$ of all epilepsy cases, which are known as posttraumatic epilepsy. Macrophage/microglia are key players in TBI pathogenesis. They are activated after $\mathrm{TBI}$, transform to inflammatory phenotype (M1) and trigger neuroinflammation, which provokes epileptogenesis. Interleukin-4 (IL-4) is a well-known polarizer of macrophage/microglia to the antiinflammatory phenotype (M2). We tested the effect of IL-4 on the rate of epileptogenesis, brain expression of inflammatory and anti-inflammatory cytokines, and the lesion size in traumatic rats. Trauma was exerted to temporo-parietal cortex of rats by Controlled Cortical Impact. Thereafter, rats received a single dose (100ng/rat) of IL-4 through intracerebroventricular injection. After $24 \mathrm{~h}$, pentylenetetrazole (PTZ) kindling started and development of generalized seizures was recorded. Level of TNF- $a$, TGF- $\beta$, IL-10, and arginase-1 (Arg-1) was measured in the brain by immunoblotting at $6 \mathrm{~h}, 12 \mathrm{~h}, 24 \mathrm{~h}$, $48 \mathrm{~h}$, and 5 days after TBI. The lesion size and cell survival were determined by staining. Traumatic rats were kindled by $5 \pm 1$ PTZ injections (significantly less than $11 \pm 2$ injections of control and sham-operated rats, $p<0.001)$. IL-4 did not change kindling rate in sham-operated rats but inhibited acceleration of kindling rate in traumatic rats $(13 \pm 1$ PTZ injections, $p<0.001)$. IL-4 decreased post-TBI overexpression of TNF-a (6h, $p<0.001)$ whereas upregulated post-TBI expression of TGF- $\beta$ (48h, $p<0.001)$, IL-10 (24h, $p<0.05$; 48h, $p<0.01)$, and Arg-1 (24h, $p<0.001)$. IL-4 decreased lesion volume and number of dead neurons. IL-4 suppresses TBI-induced acceleration of epileptogenesis in rats by directing macrophage/microglia to the anti-inflammatory M2 phenotype and inhibition of neuronal death.

\section{Introduction}

Traumatic brain injury (TBI) is an injury to the brain caused by an external force such as mechanical forces and supersonic blast waves. The global incidence of all-cause, all-severity TBI is estimated to be about $1 \%$; of which $0.74 \%$ is related to mild TBI, and $0.073 \%$ associated with severe TBI (Dewan et al., 2019). Sixty-nine million people are estimated to suffer TBI from all causes each year, with the Southeast Asian and Western Pacific regions experiencing the greatest overall burden of disease (Dewan et al., 2019).

TBI prompts an array of cellular processes that result in neuroinflammation (Woodcock and MorgantiKossmann, 2013; Hunt et al., 2013, Turtzo et al., 2014; Xiong et al., 2018). Neuroinflammation, in turn, triggers a series of pathological cascades and underlies neurological diseases such as Alzheimer's disease, Parkinson's disease, stroke, chronic traumatic encephalopathy, and epilepsy (Cruz-Haces, 2017; Webster et al., 2017; Xiong et al., 2018).

Epilepsy is a neurologic disease that has around 1\% international incidence. Post-traumatic epilepsy (PTE) is a form of acquired epilepsy. TBI is responsible of $5 \%$ of all epilepsy cases; and over than $20 \%$ of cases of acquired epilepsy (Brady et al., 2019). No strategy is yet available to avoid PTE. Neuroinflammation has a central role in PTE (Mukherjee et al., 2020; Sun et al., 2021; Sharma et al., 2021). 
Interleukin-4 (IL-4) is a cytokine serves as a potent regulator of immunity. It often acts as an antiinflammatory agent by regulating inflammation cascade toward down-regulation of the inflammatory cytokines such as TNF-a (Woodward et al., 2010) and upregulation of anti-inflammatory cytokines such as IL-10 (Liu et al., 2016; Mitchell et al., 2017). IL-4 knockout mice display increased brain injury and worsened neurological outcome after transient focal cerebral ischemia (Xiong et al., 2011) and traumatic spinal injury (Lee et al., 2010). IL-4 is able to polarize macrophage/microglia to the anti-inflammatory phenotype (Girard et al., 2013). It is found that IL-4 is produced in neurons after stroke (Li et al., 2001) and focal cerebral ischemia (Zhao et al., 2015), and modulates macrophage/microglia function by polarizing them to the M2 "healing" phenotype. In vivo alternative activating M2 macrophage/microglia by IL-4 has been of interest as a therapeutic strategy for treatment of the injury-associated neurologic diseases. In this regard, administration of IL-4 to animals with TBI and traumatic spinal cord injury has been accompanied by beneficial behavioral improvements (Lima et al., 2017; Francos-Quijorna et al., 2016; Pu et al., 2020). Meanwhile, IL-4 has been shown antiepileptic activity in the animal study. It is found that early treatment of mice by IL-4 inhibits rate of recurrent seizures in pilocarpine model of epilepsy by inhibiting early increase of M1 macrophage/microglia, and promoting the increase of M2 phenotype (Li et al., 2017).

Nevertheless, the possible inhibitory effect of IL-4 on development of PTE has not yet been examined. It is shown that TBI accelerates development of epileptogenesis in animal models (Eslami et al., 2016, Hesam et al., 2018). Accordingly, we aimed to examine impact of IL-4 on the accelerated rate of epileptogenesis in traumatic rats. We injected IL-4 to brain of rats shortly after TBI. Then, development of generalized seizures was assessed using kindling model of epileptogenesis. Given the essential role of macrophage/microglia in TBI pathogenesis, and IL-4 as the transformer of macrophage/microglia to the M2 phenotype, functional expression of arginase-1 (Arg-1) as the typical marker of M2 macrophage/microglia, as well as distinctive anti-inflammatory cytokines produced by the M2 phenotype were measured in the brain of the IL-4-treated traumatic rats.

\section{Materials And Methods}

\section{Animals}

Adult male Wistar rats (9-weeks old and 240-270 g weight, $\mathrm{n}=269$ ) were obtained from Pasteur Institute of Iran. The animals were housed in standard polypropylene cages in a room with controlled temperature $\left(23 \pm 2.0^{\circ} \mathrm{C}\right)$ and $12 \mathrm{~h}$ light/dark cycle (08:00-20:00). They were fed ad libitum with rodent's chow and free access to drinking water. Animals were randomly divided to different experimental groups. All animal experiments were carried out in accordance with the Review Board and Ethics Committee of Pasteur Institute of Iran, and Council Directive 2010/63EU of the European Parliament, and the Council of 22 September 2010 on the protection of animals used for scientific purposes.

\section{Induction of TBI}


Rats were anaesthetized with intraperitoneal (i.p.) injection of $60 \mathrm{mg} / \mathrm{kg}$ ketamine and $10 \mathrm{mg} / \mathrm{kg}$ xylazine (Alfasan, The Netherlands). A 5-mm burr hole was drilled at left parieto-temporal cortex at coordinates; A, $-4 \mathrm{~mm}$ from bregma; $\mathrm{L},-4 \mathrm{~mm}$ from bregma; according to atlas of rat brain (Paxinos and Watson, 2007). The bone was removed and TBI was induced by a Controlled Cortical Impact (CCI) device (AmScien Instruments, Model AMS 201, USA) with $5 \mathrm{~mm}$ round tip, $4.5 \mathrm{~mm} / \mathrm{s}$ velocity, $150 \mathrm{~ms}$ duration and $2 \mathrm{~mm}$ depth of deformation. Then, the dissected bone was brought back to its position on the skull, and fixed with dental acrylic. The skin was then closed. Sham-operated animals underwent the whole procedure except that they did not received $\mathrm{CCl}$ injury.

\section{Intracerebroventricular injection of IL-4}

IL-4 (eBioscience, USA) was dissolved in phosphate-buffered saline (PBS). It is injected ( $100 \mathrm{ng} / 5 \mu \mathrm{l} / \mathrm{rat}$ ) into the right lateral ventricle (i.c. v; AP, $-0.9 \mathrm{~mm}$ from bregma; $\mathrm{L}, 1.7 \mathrm{~mm}$ from bregma; $V, 3.5 \mathrm{~mm}$ from dura) of the anesthetized rats through a 27-gauge needle that was fitted to a Hamilton microsyringe. The dose of IL-4 was selected based on the effective doses used in trauma and stroke studies (Cherry et al., 2014; Liu et al., 2016)

\section{Pentylenetetrazole kindling}

Twenty-four h after TBI or sham operation, rats received $35 \mathrm{mg} / \mathrm{kg}$ pentylenetetrazole, (PTZ, SigmaAldrich, Canada) though i.p. route. PTZ injections were repeated every $48 \mathrm{~h}$ until generalized seizures were developed in rats in 3 sequential PTZ injections. The seizure behaviors were scored according to Racine's classification (Racine, 1972). Forelimbs clonic seizures associated with rearing (score 4), and generalized convulsions with loss of balance (score 5) were considered as generalized seizures.

\section{Histology}

\section{2, 3, 5-Triphenyl tetrazolium chloride staining}

The depth and volume of brain contusion was evaluated after $\mathrm{CCl}$ by 2, 3, 5-Triphenyl tetrazolium chloride (TTC; Sigma-Aldrich, Canada) staining according to previously described method (Eslami et al., 2015). The animals were euthanized by $\mathrm{CO} 2$ asphyxiation. Brains were quickly removed and cut freshly into 2 $\mathrm{mm}$ coronal sections by a rat brain matrix. The slices were instantly immersed in $2 \%(\mathrm{w} / \mathrm{v}$ in $0.9 \% \mathrm{NaCl})$ TTC at $37^{\circ} \mathrm{C}$ for $10 \mathrm{~min}$. The area with no staining was determined as the damaged area. The nonstained area as well as the whole area of each section was scanned by Image $\mathrm{J}$ software, version 1.8 (National Institute of Health). The depth of lesion was determined. Volume of section and volume of lesion area of that section were calculated by multiplying their area by the thickness $(2 \mathrm{~mm})$. The whole lesion volume was determined by summing lesion volume of the sections. Data are presented as mean ratio of whole lesion volume to the whole volume of the relevant sections.

\section{Fluorescent staining}

The viable cells in the traumatic area were assessed by hematoxylin \& eosin (H\&E), and propidium iodide (PI) staining. The animals ( 3 rats in each group) were euthanized by $\mathrm{CO} 2$ asphyxiation and immediately 
perfused transcardially with $4 \%$ paraformaldehyde in $0.1 \mathrm{M} \mathrm{PBS}$. The brains were harvested, kept in $4 \%$ paraformaldehyde in 0.1 M PBS and processed for embedding in paraffin blocks. The brains were then cut horizontally to $8 \mu \mathrm{m}$ thickness. The sections were deparaffinized, rehydrated in a descending alcohol series and stained with PI (1:1000 in Tris-buffered saline, Sigmaaldrich Germany) for $30 \mathrm{~s}$, and or H\&E. The sections were cover-slipped with $90 \%$ glycerol mounting buffer. The H\&E-stained sections were visualized with light microscope (Nikon, Japan). The PI-stained sections were visualized in the dark place with fluorescent microscope (Nikon, Japan) equipped with specific filter cube for fluorescence channels, and connected to a digital camera. Digital photographs were taken using $4 \mathrm{x}$ and $10 \mathrm{x}$ objective lenses. The number of Pl-stained cells were counted in the traumatic area of every 10 sections $(5 \mathrm{~mm}$ width and $2.2 \mathrm{~mm}$ depth from cerebral cortex) by computer-assisted imaging program (Image J, version 1.8). Data are presented as mean number of viable cells per section.

\section{Western blotting}

A 5-mm ${ }^{3}$ piece of the left parieto-temporal cortex at the site of trauma injury was cut up and protein concentration of the tissue homogenate was determined by Bradford assay (Bradford, 1976). Twenty $\mu \mathrm{g}$ of total protein was electrophoresed in 15\% SDS-PAGE gel, then transferred to polyvinylidene difluoride membrane and probed with the primary monoclonal antibodies of TNF-a, Arg-1, IL-10 (1:1000 dilution; Santa Cruz Biotechnology, USA), TGF- $\beta$ (1:1000 dilution; Sigmaaldrich, Germany), and $\beta$-actin (1:2000 dilution; Invitrogen, USA) as internal control. After washing, the membrane was incubated with peroxidase conjugated rabbit anti-rat IgG (1:50000; Invitrogen, USA). Immunoreactive polypeptides were detected by chemiluminescence using electrochemiluminescence reagents (Amersham Bioscience, UK) and subsequent autoradiography. Quanti $\llbracket$ cation of results was performed by densitometry scan of the $\square \mathrm{lms}$ using Image $\mathrm{J}$ software, version 1.8. The relative level of the assessed polypeptide was expressed as ratio of the polypeptide blot density to the $\beta$-actin blot density.

\section{Experimental design}

Five experimental groups with 9 rats in each group were assigned for kindling procedure. Group 1 (as control) included intact rats which underwent PTZ kindling. Group 2 (as sham) consisted of rats which underwent craniotomy with no TBI induction. Then they received PBS $(5 \mu \mathrm{l} / \mathrm{rat}$, i.c.v., up to $30 \mathrm{~min}$ after craniotomy), and chemical kindling started $24 \mathrm{~h}$ thereafter. In group 3 (IL-4) rats received IL-4 (100ng/5 $\mathrm{\mu l} / \mathrm{rat}$, i.c. v.), and after $24 \mathrm{~h}$ kindling procedure started. Group 4 (Trauma) included rats which underwent TBI, and after $24 \mathrm{~h}$ kindling procedure started. In group 5 (IL-4 + Trauma) rats underwent TBI. Then they received IL-4 (100ng/5 $\mu \mathrm{l} /$ rat, i.c.v., up to $30 \mathrm{~min}$ after TBI), and chemical kindling started $24 \mathrm{~h}$ thereafter.

In order to determine the time course of the polypeptides expression after TBI, 13 experimental groups with 8 rats in each group were allocated for western blotting. These groups consist of control (intact rats), sham (including 6 subgroups), and trauma (including 6 subgroups). In sham and trauma subgroups, brains were harvested at $3,6,12,24$, and $48 \mathrm{~h}$ as well as 5 days after sham operation or induction of TBI. 
To determine effect of IL-4 on polypeptides expression, 6 experimental groups with 8 rats in each group were assigned. There were 3 "Sham + IL-4" groups in which animals underwent craniotomy with no trauma induction. Then, they received IL-4 $(100 \mathrm{ng} / 5 \mu \mathrm{l} / \mathrm{rat}$, i.c.v.) after craniotomy. The brain of rats was harvested at 6, 24, and $48 \mathrm{~h}$ after craniotomy. The 3 other groups were "Trauma + IL-4" groups in which

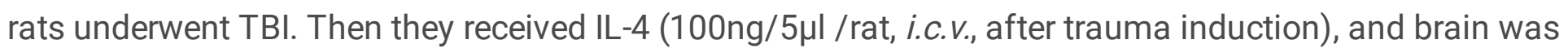
harvested 6,24 , and $48 \mathrm{~h}$ thereafter.

In order to determine time course of lesion development after TBI and effect of IL-4 on lesion volume, 8 experimental groups with 8 rats in each group were allocated. Three groups were considered as sham, and 3 groups were assigned as trauma. Brain of rats was harvested at 24, and $48 \mathrm{~h}$ as well as 5 days after sham operation or induction of TBI. In the last two groups effect of IL-4 on lesion volume was assessed. Rats underwent TBI. Then they received IL-4 (100ng/5 $\mu \mathrm{l} /$ rat, i.c.v., after trauma induction), and brain was harvested 24 , and $48 \mathrm{~h}$ thereafter. All the brains were then stained by TTC and injury volume was measured.

In order to determine the effect of IL-4 on cell survival after trauma, 6 experimental groups with 3 rats in each group were allocated. Two groups were considered as sham, and 2 groups were assigned as trauma. The brain was harvested at 24 , and $48 \mathrm{~h}$ after sham operation or induction of TBI. In the remaining two groups effect of IL-4 on cell viability was assessed. Rats underwent TBI. Then they received IL-4 (100ng/5 $\mu \mathrm{l} / \mathrm{rat}$, i.c. v., after trauma induction), and the brain was harvested 24 , and $48 \mathrm{~h}$ thereafter. All the brains were then stained by H\&E and PI and number of viable cells was determined.

\section{Statistical analysis}

All statistical analyses were performed using Graph Pad Prism 8 Software. Kaplan-Meier survival analysis was performed for PTZ kindling experiments. One-way ANOVA with Tukey-Kramer multiple comparisons test was used to analyze number of PTZ injections required to kindle rats, and the lesion volume. In order to determine significant interaction between treatment and time factors in the PI staining, and Western blot data, two-way ANOVA and multiple comparisons test were used. The results were expressed as mean \pm SEM (standard error of mean) and the differences with $p$ values less than 0.05 were considered statistically significant.

\section{Results}

\section{IL-4 inhibited the accelerated rate of kindling in traumatic rats}

During kindling experiment 3 rats of the trauma group were excluded due to death after trauma. The data of one rat from control and one rat from sham groups were excluded from results due to out of range values. A Kaplan-Meier survival analysis showed that traumatic rats became kindled significantly $(p<$ 0.05; Log-rank Mantel-Cox test) earlier than the sham or control rats (Fig. 1A). Treatment of traumatic rats with IL-4 reversed the accelerated rate of kindling epileptogenesis. Animals in control and sham groups 
became kindled with the similar rate with the mean number of 11 PTZ injections (Fig. 1B). Non-traumatic rats that received IL-4 were kindled after around 9 PTZ injections. However, there was no significant difference between IL-4, control and sham groups in number of injections. TBI significantly accelerated development of kindling as traumatic rats were kindled after just 5 injections $(p<0.001$ compared to control and sham groups). Rats which received IL-4 after trauma became kindled after mean number of 13 PTZ injections, which was more than that of sham and control groups. However, it was not significant compared to sham and control groups.

\section{Effect of IL-4 on brain lesion volume and cell viability in the traumatic rats}

With the severity applied in our study, $\mathrm{CCl}$ induced $2 \pm 0.5 \mathrm{~mm}$ depth of deformation from dura $24 \mathrm{~h}$ and $48 \mathrm{~h}$ after $\mathrm{CCl}$ (Fig. 2). A lesion with $0.21 \mathrm{~mm}^{3}$ mean volume developed $24 \mathrm{~h}$ after $\mathrm{CCl}$ and preserved till 48h. One way ANOVA revealed a significant difference between groups $[F(7,34)=37.99, p<0.0001)$.

Then the mean lesion volume decreased to $0.14 \mathrm{~mm}^{3} 5$ days after trauma but it still had significant difference with the corresponding sham group ( $p<0.01$, Fig. 2$)$. Treatment of traumatic rats with IL-4 decreased lesion volume. IL-4 significantly decreased injury volume $48 \mathrm{~h}$ after TBI $(p<0.05)$.

Effect of TBI and IL-4 on the number of PI-positive cells in the traumatic region is demonstrated in Fig. 3. PI positive cells were significantly decreased $24 \mathrm{~h}(p<0.01)$ and $48 \mathrm{~h}(p<0.001)$ after TBI. Two-way ANOVA revealed a significant interaction $[\mathrm{F}(3,16)=3.88, p<0.05]$ between treatment $([\mathrm{F}(3,16)=33.86$, $p<0.0001)$ and time ( $[\mathrm{F}(1,16)=7.67, p=0.013)$ factors among groups. Administration of IL-4 to traumatic rats did not significantly change the number of PI-positive cells at $24 \mathrm{~h}$ after TBI. However, at the $48 \mathrm{~h}$ post-TBI period, number of PI-positive cells in the IL-4-treated traumatic rats was significantly higher than that of the traumatic rats $(p<0.05)$.

\section{IL-4 prevented overexpression of TNF-a $6 \mathrm{~h}$ after TBI}

Figure 4A demonstrates time course of TNF-a protein expression from $3 \mathrm{~h}$ to 5 days after TBI. TNF-a significantly increased at early times ( $3 \mathrm{~h}$ and $6 \mathrm{~h}$ ) after $\mathrm{TBI}$, and returned to control level $24 \mathrm{~h}$ thereafter. Two-way ANOVA revealed a significant interaction $[\mathrm{F}(3,16)=42.86, p<0.0001]$ between treatment $([\mathrm{F}(1$, $16)=63.35, p<0.0001)$ and time $([\mathrm{F}(3,16)=73.77, p<0.0001)$ factors among groups. The $6 \mathrm{~h}$ post-TBI period was selected to evaluate the effect of IL-4 on TNF-a expression.

As shown in Fig. 4B, One way ANOVA revealed a significant difference between groups $[\mathrm{F}(3,8)=280.1, p$ $<0.0001$ ). Administration of IL-4 to sham-operated rats (sham + IL-4 group) increased TNF-a expression after $6 \mathrm{~h}$ ( $p<0.01$, compared to sham group). However, administration of IL-4 to traumatic rats inhibited overexpression of TNF- $a$ at this time point. A significant difference was found between traumatic rats and IL-4-treated traumatic rats $(p<0.0001)$ in TNF-a level.

\section{IL-4 augmented overexpression of IL-10 after TBI}


The time course of IL-10 protein expression after TBI is demonstrated in Fig. 5A. IL-10 significantly increased $6 \mathrm{~h}$ after $\mathrm{CCl}$. This increase lasted up to $24 \mathrm{~h}$ after TBI. Two-way ANOVA revealed a significant interaction $[F(6,60)=16.37, p<0.0001]$ between treatment $([F(2,60)=230.6, p<0.0001)$ and time $([F(3$, $60)=20.7, p<0.0001)$ factors among groups.

The $24 \mathrm{~h}$ and $48 \mathrm{~h}$ periods after TBI were selected to assess the effect of IL-4 on IL-10 expression. Twoway ANOVA revealed a significant interaction $[\mathrm{F}(3,40)=111.3, p<0.0001]$ between treatment $([\mathrm{F}(3,40)$ $=168.3, p<0.0001)$ and time $([\mathrm{F}(1,40)=28.12, p<0.0001)$ factors among groups (Fig. 5B).

Administration of IL-4 to sham-operated rats (sham + IL-4 group) significantly increased IL-10 expression after $48 \mathrm{~h}$ ( $p<0.0001$ compared to the corresponding sham group). The extent of IL-10 expression at $48 \mathrm{~h}$ was significantly higher than that at $24 \mathrm{~h}$ after sham operation $(p<0.0001)$. Administration of IL-4 to traumatic rats significantly amplified overexpression of IL-10 at both $24 \mathrm{~h}$ and $48 \mathrm{~h}$ after TBI $(p<0.0001$ compared to the corresponding Trauma group).

\section{IL-4 amplified overexpression of TGF- $\beta$ 48h after TBI}

The time course of TGF- $\beta$ protein expression after TBI is demonstrated in Fig. 6A. TGF- $\beta$ significantly increased $6 \mathrm{~h}$ after $\mathrm{CCl}$, persisted for $24 \mathrm{~h}$ and then decreased to a level less than control at $48 \mathrm{~h}$ after TBI $(p<0.0001)$. Two-way ANOVA revealed a significant interaction $[F(4,18)=241.7, p<0.0001]$ between treatment $([F(2,18)=206.5, p<0.0001)$ and time $([F(2,18)=297.5, p<0.0001)$ factors among groups.

The 24h and 48h periods after TBI were selected to evaluate effect of IL-4 on TGF- $\beta$ expression. Two-way ANOVA revealed a significant interaction $[F(3,16)=28.59, p<0.0001]$ between treatment $([\mathrm{F}(3,16)=$ $54.62, p<0.0001)$ and time $([\mathrm{F}(1,16)=25.34, p<0.001)$ factors among groups (Fig. 6B). Administration of IL-4 to sham-operated rats (sham + IL-4 group) did not change TGF- $\beta$ expression after both $24 \mathrm{~h}$ and $48 \mathrm{~h}$. Administration of IL-4 to traumatic rats significantly amplified overexpression of IL-10 at $48 \mathrm{~h}$ after TBI $(p<0.001)$. There was no significant difference between the $24 \mathrm{~h}$ and $48 \mathrm{~h}$ trauma groups receiving IL4.

\section{IL-4 increased expression of Arg-1 in the traumatic brain}

As seen in Fig. 7, expression of Arg-1 significantly increased 24h $(\mathrm{p}<0.0001)$, but not $48 \mathrm{~h}$ after TBI. Twoway ANOVA revealed a significant interaction $[\mathrm{F}(3,24)=22.79, p<0.0001]$ between treatment $([\mathrm{F}(3,24)$ $=108.2, p<0.0001)$ and time $([\mathrm{F}(1,24)=58.83, p<0.0001)$ factors among groups. Administration of IL4 to sham-operated rats increased $A r g-1$ expression after $24 \mathrm{~h}(p<0.0001)$ but not $48 \mathrm{~h}$. Administration of IL-4 to traumatic rats significantly amplified overexpression of $A r g-1$ at $48 \mathrm{~h}$ after TBI $(p<0.0001)$. There was significant difference between the $24 \mathrm{~h}$ and $48 \mathrm{~h}$ trauma groups receiving IL-4 $(p<0.01)$.

\section{Discussion}

The present study implies that the accelerating effect of TBI on development of kindled seizures is inhibited by single i.c.v. injection of IL-4 shortly after TBI. IL-4 could reduce lesion size, and significantly rescue neurons from death in traumatic rats. IL-4 also suppressed expression of the M1 cytokine TNF-a. 
Moreover, IL-4 amplified overexpression of the M2 cytokines IL-10, and TGF- $\beta$, and the M2 marker Arg- 1 in the damaged area. Therefore, directing TBI neuroinflammation toward an anti-inflammatory tone seems to be mainly involved in the blunting effect of IL-4 on the accelerated epileptogenesis in TBI context.

It is reported that intraperitoneal administration of IL-4 to mice $5 \mathrm{~h}$ before and 4 days after induction of epilepsy by pilocarpine could decrease frequency of seizures and inhibits development of epilepsy (Li et al., 2017). Therefore, we first assessed the ineffective dose of IL-4 on kindling rate in non-traumatic rats. In addition, we intended to exclude potential effect of IL-4 on peripheral immune system. Therefore, the i.c.v. route of administration was selected. Given that antiepileptogenic interventions are necessary after the presumed epileptogenic insult, in order to translate the drug-therapy protocol into practical clinical application, we administered IL-4 shortly after TBI. IL-4, 100ng/rat, slightly decreased the rate of kindling epileptogenesis. However, this effect was not statistically significant. Therefore, we examined the effect of this dose on development of kindled seizures in traumatic rats. IL-4 could successfully inhibit acceleration of kindling development in TBI state. The present study is the first report indicating that IL-4 if is administered for a while after trauma is able to prevent acceleration of epileptogenesis in traumatic rats. There are indirect studies that support finding of the present study. It is reported that the bacterial endotoxin LPS and its derivative monophosphoryl lipid A inhibit the increased potential for acquisition of seizures in traumatic rats (Eslami et al., 2015; Hesam et al., 2018). LPS can stimulate de novo IL-4 gene expression in murine microglia both in vitro and in vivo (Mukherjee et al., 2009; Lively and Schlichter, 2018). Moreover, LPS is able to induce M2 polarization through a time-dependent (Zhang et al., 2019) and species-dependent manner (Orecchioni et al., 2019). However, LPS is too toxic to be introduced in human clinical trials. In contrast to LPS, clinical studies suggest that IL-4 has acceptable safety. Clinical trials state recombinant IL-4 is safe and well tolerated in humans at the doses of $0.25-5 \mu \mathrm{g} / \mathrm{kg} / \mathrm{day}$ and up to $10 \mu \mathrm{g} / \mathrm{kg}$ once administered 3 times/week (Leach et al., 1997; Vokes et al., 1998). Therefore, IL-4 may have significant clinical relevance for prevention of PTE.

There is strong evidence on the beneficial impacts of IL-4 on tissue repair following brain injury (Mantovani et al., 2013; Salmon-Her et al., 2000; Xiong et al., 2011). It is shown that administration of IL-4 $48 \mathrm{~h}$ after spinal cord injury (SCl) markedly improves functional outcomes and reduces tissue damage after contusion injury (Francos-Quijorna et al., 2016). Therefore, we first examined the possible impact of IL-4 on TBI size as the primary mechanism of anti-epileptogenic effect of IL-4 in the TBI state. In our study, TTC staining showed a remarkable cortical injury $24 \mathrm{~h}$ after $\mathrm{CCl}$. The size of the injured tissue did not expand at $48 \mathrm{~h}$ post-TBI period. Then, 5 days after TBI, the injured area showed a size reduction. Our results are in agreement with the study by Başkaya et al., (2000). They showed that CCI with moderate severity ( $2 \mathrm{~mm}$ deformation depth) induces maximum cortical injury in rats after 1 and 2 days. Similar to our results, they found a gradual decrease in the lesion volume starting from day 4 and then a constant injury volume was observed from day 5 till 7 . In our study, treatment of traumatic rats with IL-4 caused significant reduction in injured size at $48 \mathrm{~h}$ post-TBI period. This finding is in line with the beneficial preventive effects of IL-4 on lesion development after SCI (Francos-Quijorna et al., 2016). Some research groups suggested that TTC staining has low power and cannot detect the tissue viability below a limit because the cells that are between death and survival cannot be detected by this method (Benedek et al., 
2006). Moreover, this technique is only able to detect irreversible brain damage (Liszczak et al., 1984). At the same time, it is reported that despite protective effect on both neuronal and oligodendrocyte populations, IL-4 could not reduce the size of the injured tissue in SCI (Lima et al., 2017). In order to further verify the potential protective effect of IL-4 against TBI-induced tissue injury, we examined cell viability in the trauma area by PI staining. Administration of IL-4 (100 ng/rat, i.c.v.) after TBI significantly prevented development of neuronal death $48 \mathrm{~h}$ after TBI. This finding is correlated with reduction of the injured size by IL-4 at $48 \mathrm{~h}$ post-TBI period. In contrast to our results, intrahippocampal injection of mesenchymal stromal cells transiently expressing $100 \mathrm{ng} \mathrm{IL-4,} 5$ days after TBI could not reduce hippocampal and cortical neurodegeneration and improve functional outcomes in mice (Enam et al., 2020). The early times after TBI are critical in subsiding development of TBI pathogenesis. Regardless of the tool used to deliver IL-4 into the CNS, we injected IL-4 acutely, up to $15 \mathrm{~min}$, after TBI. This period is quite early compared to the 5 days post-TBI period of IL-4 injection used by Enam et al. This might be the main reason of positive results obtained in our study. It is known that IL-4 inhibits cell death and apoptosis (Zamorano et al., 1996). IL-4 also enhances survival of murine basophils (Reinhart and Kaufmann, 2018) and mast cells (Burton et al., 2013). Various mechanisms are suggested for this attribute of IL-4 (Zamorano et al., 1996; Reinhart and Kaufmann, 2018; Chen et al., 2020). In cerebral ischemic-reperfusion injury, which is associated with hyperexcitablity of neurons and cell death, supplemental IL-4 has been able to increase viability of cortical neurons by reducing spontaneous neuronal firing and network burst activity (Chen et al., 2020). This mechanism seems to be also involved in the preserving viability of neurons by IL-4 in our study. This suggestion is supported by the behavioral finding of our study as IL-4 could decrease brain hyperexcitablity and the accelerated rate of kindling epileptogenesis induced by TBI.

TBI is obviously associated with acute neuroinflammation and release of inflammatory cytokines. Neuroinflammation is the main causative factor in PTE (Mukherjee et al., 2020; Sun et al., 2021). Therefore, modulation of neuroinflammation would have major role in preventing PTE. Hence, we measured impact of IL-4 on the TBI-induced brain expression of TNF-a, as the typical inflammatory cytokine, and IL-10 as well as TGF- $\beta$, as the classic anti-inflammatory cytokines. Our results showed that TNF-a protein level increased in the traumatic brain to a level more than twice of the sham level at 3 and $6 \mathrm{~h}$ after TBI. Then the TNF-a level returned to sham level $24 \mathrm{~h}$ after TBI. This finding is consistent with previous studies demonstrating the increase of TNF-a protein level in rat brain during a 3-12 $\mathrm{h}$ period after CCl (Eslami et al., 2015) and fluid percussion injury (Taupin et al., 1993; Clausen et al., 2019). We selected the $6 \mathrm{~h}$ post-CCl interval, and measured TNF-a brain expression after treatment of traumatic rats with IL-4. IL-4 by itself increased TNF-a level in the sham-operated rats. This is the first report indicating increase in TNF-a level in sham (control) group by IL-4. This finding is in contrast to the previous report indicating that IL4 does not change TNF-a level in control conditions such as unstimulated monocytes (Hart et al., 1988). The difference in doses of IL-4 and conditions of the two studies (in vivo versus in vitro) might be the underlying reason for the different findings. IL-4 is predominantly regarded as an anti-inflammatory cytokine. However, there are in vitro and in vivo evidence suggesting that IL-4 by itself can also promote the inflammatory response including TNF- $\alpha$ and IL-1 $\beta$ expression in parallel (Latta et al., 2015; Ratthé et 
al., 2009; Van Kampen et al., 2005). The target cell, the time of application, and concentration during various phases of immune responses are determinant of pro- or anti-inflammatory effects of IL-4. The TNF-a increase by IL-4 in the sham-operated rats, is in line with the kindling data of the present study. IL-4 increased the rate of epileptogenesis in sham-operated rats, which was marginally significant $(p=0.05)$. Given the proconvulsant effect of TNF-a (Chong et al., 2018; Lagarde et al., 2016; Riazi et al., 2008), the increased expression of TNF-a (and other inflammatory cytokines such as IL-1 $\beta$ ) seems to be mainly involved in the acceleration of kindling development by IL-4 in non-traumatic rats. On the other hand, IL-4 blocked the increase in TNF-a level after TBI. Anti-inflammatory activity of IL-4 is attributed to suppression of TNF- $\alpha$ and interleukin 1- $\beta$ production and activity (Hart et al., 1989; Leving et al., 1999). Considering the positive impact of TNF-a on seizure threshold and epileptogenesis (Chong et al., 2018; Patel et al., 2017; Rana and Musto, 2018) the suppressing effect of IL-4 on the acceleration of kindling development by TBI is mediated (in part) via inhibiting TNF-a increase in the traumatic brain area.

In order to verify impact of IL-4 on expression of the classic anti-inflammatory cytokines L-10 and TGF- $\beta$ after TBI, the time course of expression of these cytokines was first determined. IL-10 level increased $12 \mathrm{~h}$ after TBI, and remained higher than basal level till $48 \mathrm{~h}$. TGF- $\beta$ showed different pattern of expression. The level increased 6 and $24 \mathrm{~h}$ after TBI but then decreased to the level less than control at $48 \mathrm{~h}$ after TBI. IL-10 is shown modest elevation in mice $24 \mathrm{~h}$ after CCl with the peak 3 days after CCl (Lagraoui et al., 2012). However, in a weight drop model of TBI in rats, IL-10 acutely raised in brain from $2 \mathrm{~h}$ after trauma followed by a progressive increase over $24 \mathrm{~h}$ (Kamm et al., 2006). These findings demonstrate variability in the degree of cytokine response based on the mechanism and severity of injury. Then, we determined the effect of IL- 4 on brain expression of IL-10 and TGF- $\beta$ at $24 \mathrm{~h}$ (the time of rise in both cytokines) and $48 \mathrm{~h}$ (the time of decline in both cytokines) after TBI. At both $24 \mathrm{~h}$ and $48 \mathrm{~h}$ after sham operation, IL-4 had no effect on TGF- $\beta$ brain level but increased IL-10 brain level. IL-4 has induced IL-10 expression from stimulated T helper 1 cells (Mitchell et al., 2017) as well as endotoxin-stimulated monocytes/microglia (Kambayashi et al., 1996; Cao et al., 2005) but not from unstimulated (control) cells. We report for the first time that IL-4 is able to induce IL-10 production in control condition in vivo. Administration of IL-4 to traumatic rats significantly intensified IL-10 expression at both $24 \mathrm{~h}$ and $48 \mathrm{~h}$ post-CCI periods. IL-10 is a well-known anti-inflammatory cytokine which is expressed following TBI. IL-10 inhibits development of epileptiform activity evoked by transient episodes of hypoxia in rat hippocampal slices (Levin and Godukhin, 2007), and focal convulsions in electrical kindling (Godukhin et al., 2009). IL-10 can also increase threshold of temperature-induced seizures in rats (Ishizaki et al., 2009). Thus, amplification of IL10 expression by IL-4 plays a role in suppressing the TBI-induced acceleration of kindling development. With regard to TGF- $\beta$, IL-4 did not affect the increased TGF- $\beta$ expression in traumatic rats $24 \mathrm{~h}$ after TBI but could significantly raise TGF- $\beta$ expression at $48 \mathrm{~h}$ (the time of fall in the cytokine level after TBI) postTBI period. TGF- $\beta$ possesses both pro- and anti-inflammatory functions depending on the context. TGF- $\beta$ is involved in epilepsy and PTE. Over-expression of cerebral TGF- $\beta$ in transgenic mice causes development of a set of neuropathological complications including seizures (Wyss-Coray et al., 1995). Moreover, TGF- $\beta$ and TGF- $\beta$ signaling pathway are demonstrated among the main elements in development of epileptiform activity in rats after the brain injury induced by blood brain barrier disruption 
(Cacheaux et al., 2009). TGF- $\beta$ is overexpressed 3 days after CCl in mice, and i.p. injection of TGF- $\beta$ blocker is associated with a decrease in seizure behavior and EEG power spectrum (Wang et al., 2017). On the other hand, TGF- $\beta$ has shown neuroprotective action against glutamate neurotoxicity and ischemic brain injury (Prehn et al., 1993). The genetic defects in the TGF- $\beta$ pathway is accompanied by epilepsy in humans (Kotlarz et al., 2018). Moreover, inhibition of TGF- $\beta$ signaling blocks the anti-seizure effects of the oligonucleotide miRNA inhibitors (antagomirs) in three different rodent models of temporal lobe epilepsy (Venø et al., 2020). Thus, strengthening the TGF- $\beta$ expression by IL-4 also seems to play a role in suppression of TBI-induced acceleration of kindling development. Given the central role of neuroinflammation in pathogenesis of PTE (Mukherjee et al., 2020; Sun et al., 2021), amplification of antiinflammatory response greatly contributes in the suppressing impact of IL-4 on TBI-induced acceleration of kindling development.

We found that administration of II-4 shortly after TBI causes overexpression of IL-10 and TGF- $\beta$, and impedes expression of TNF- $a$. TNF- $a$ is the typical proinflammatory cytokine released from M1 macrophage/microglia, whereas IL-10/TGF- $\beta$ are the representative cytokines of M2 macrophage/microglia (Zhou et al., 2012, Laffer et al., 2019; Yao et al., 2019). Therefore, we assessed potential polarization of macrophage/microglia to $\mathrm{M} 2$ phenotype by measuring brain expression of the classic marker of M2 macrophage/microglia Arg-1. In our study, TBI itself was associated with Arg-1 overexpression in $24 \mathrm{~h}$ but not $48 \mathrm{~h}$ after TBI. Overexpression of $\mathrm{Arg}-124 \mathrm{~h}$ after TBI is comparable with the period of overexpression of M2 cytokines IL-10 and TGF- $\beta$ after TBI as they also enhanced in our study during first $24 \mathrm{~h}$ after TBI. It is reported that in addition to M2 phenotype, Arg-1 is also upregulated in a fraction of murine M1 macrophage as well (Amici et al., 2017). Therefore, in addition to M2 phenotype, M1 inflammatory macrophage/microglia might be another source of Arg-1 expression in the brain of traumatic rats. In a study similar to ours, Turtzo et al., utilized CCI model of trauma and measured the cytokine expression at post-transcription level (Turtzo et al., 2014). However, they found a 5-7 days post-TBI period for microglia mixed M1 and M2 response in rats (Turtzo et al., 2014). In contrast to our study, they used female rats. Macrophage/microglia response in vivo is highly complex depending on many factors, of which gender differences is critical and seems to be the key reason for different macrophage/microglia time response between the two studies.

In our study, administration of IL-4 to sham-operated (non-traumatic) rats significantly increased expression of Arg-1 after 24h. This stimulatory effect on Arg-1 was not seen at $48 \mathrm{~h}$ after administration, which is most likely due to short half-life of IL-4 (Conlon et al., 1989). Our finding is in line with previous study indicating temporal upregulation of $A r g-1$ in frontal cortex and striatum microglia of naïve control rats 8-16h after direct injection of IL-4 into the third ventricle (Pepe et al., 2014). In addition, lentiviral delivery of IL-4 into the fourth ventricle of naïve control mice has been associated with overexpression of Arg-1 of spinal cord microglia at posttranscriptional level (Rossi et al., 2018). In contrast to the time effect of IL-4 in control non-traumatic rats, we observed IL-4 administration to traumatic rats could increase Arg1 expression $48 \mathrm{~h}$ but not $24 \mathrm{~h}$ after TBI. It is recently reported that injection of IL-4 to the hippocampus of mice 5 days after head-closed injury could not significantly increase M2-like macrophages after $48 \mathrm{~h}$ (Enam et al., 2020). In our study overexpression of $\mathrm{Arg}-1$ in traumatic rats $48 \mathrm{~h}$ after IL-4 administration is 
associated with increased TGF- $\beta$ expression at this time point. However, IL-10 was overexpressed both 24 $\mathrm{h}$ and $48 \mathrm{~h}$ after IL-4 administration to traumatic rats. There is a range of activation states for microglial cells that span from the M1 to the M2 phenotypes, and the phenotype of the activated microglia will fall somewhere along this spectrum depending on the signal encountered. Moreover, the in vivo effects of IL4 are also complex, and the final response depends on the local environment, pathological state, and the doses used. These factors might be responsible for different pattern of expression of Arg-1, IL-10 and TGF- $\beta$ in the traumatic rats after IL-4 administration.

Macrophages (both resident and the invaded blood borne) as well as microglia have critical role in TBI (Hirschberg and Schwartz, 1995; Kumar and Loane, 2012). Meanwhile, IL-4 directly or indirectly attracts monocytes/macrophages from the hematopoietic system to infiltrate the CNS (Rossi et al., 2018). Although macrophage may differ from microglia for their capability to respond to IL-4 signaling, they share common markers and secreted cytokines (Rossi et al., 2018). Therefore, we cannot discriminate between the extent of contribution from microglia and from macrophages to the finding of the present study. Though many methods have been developed for distinguishing between macrophages and microglia, they are challenging and inconclusive. Hence, we used the term macrophage/microglia throughout the text.

We conclude that a single i.c.V. administration of IL-4 suppresses accelerated rate of kindling epileptogenesis in traumatic rats. Various mechanisms are involved in this finding. IL-4 capability to polarize macrophage/microglia to the M2 anti-inflammatory phenotype, blocking inflammation cascade, initiating anti-inflammation processes, and protecting cells from death are supported by our study.

\section{Declarations}

\section{Author contribution}

Study concept and design: MS. Acquisition of data: MR, BK, and TA. Analysis and interpretation of data: MS, HGP, and MR. Drafting the manuscript: MS. Experimental design and statistical analysis: MS, HGP, and MR. Obtained funding: MS. Administrative, technical, and material support: MS. Study supervision: MS. All authors had full access to all the data in the study and take responsibility for the integrity of the data and the accuracy of the data analysis.

\section{Funding}

Research reported in this publication was supported by Elite Researcher Grant Committee under award number [943697] from the National Institute for Medical Research Development (NIMAD), Tehran, Iran.

\section{Data Availability}

The data that support the findings of this study are available from the corresponding author upon reasonable request. 


\section{Ethics Approval}

All animal experiments were carried out in accordance with the Review Board and Ethics Committee of Pasteur Institute of Iran, and Council Directive 2010/63EU of the European Parliament, and the Council of 22 September 2010 on the protection of animals used for scientific purposes.

\section{Competing Interest}

The authors declare that they have no known competing financial interests or personal relationships that could have appeared to influence the work reported in this paper.

\section{Consent to participate}

Not applicable.

\section{Consent for publication}

Not applicable.

\section{Acknowledgements}

Not applicable.

\section{References}

1. Amici SA, Dong J, Guerau-de-Arellano M. Molecular Mechanisms Modulating the Phenotype of Macrophages and Microglia. Front Immunol. 2017 Nov 10;8:1520. doi: 10.3389/fimmu.2017.01520. PMID: 29176977; PMCID: PMC5686097.

2. Başkaya MK, Doğan A, Temiz C, Dempsey RJ. Application of 2,3,5-triphenyltetrazolium chloride staining to evaluate injury volume after controlled cortical impact brain injury: role of brain edema in evolution of injury volume. J Neurotrauma. 2000 Jan;17(1):93-9. doi: 10.1089/neu.2000.17.93. PMID: 10674761.

3. Benedek A, Móricz K, Jurányi Z, Gigler G, Lévay G, Hársing LG Jr, Mátyus P, Szénási G, Albert M. Use of TTC staining for the evaluation of tissue injury in the early phases of reperfusion after focal cerebral ischemia in rats. Brain Res. 2006 Oct 20;1116(1):159-65. doi: 10.1016/j.brainres.2006.07.123. Epub 2006 Sep 6. PMID: 16952339.

4. Bradford MM. A rapid and sensitive method for the quantitation of microgram quantities of protein utilizing the principle of protein-dye binding. Anal Biochem. 1976 May 7;72:248-54. doi: 10.1006/abio.1976.9999. PMID: 942051.

5. Brady RD, Casillas-Espinosa PM, Agoston DV, Bertram EH, Kamnaksh A, Semple BD, Shultz SR. Modelling traumatic brain injury and posttraumatic epilepsy in rodents. Neurobiol Dis. 2019 
Mar;123:8-19. doi: 10.1016/j.nbd.2018.08.007. Epub 2018 Aug 16. PMID: 30121231; PMCID: PMC6348144.

6. Burton OT, Darling AR, Zhou JS, Noval-Rivas M, Jones TG, Gurish MF, Chatila TA, Oettgen HC. Direct effects of IL-4 on mast cells drive their intestinal expansion and increase susceptibility to anaphylaxis in a murine model of food allergy. Mucosal Immunol. 2013 Jul;6(4):740-50. doi: 10.1038/mi.2012.112. Epub 2012 Nov 14. PMID: 23149659; PMCID: PMC3600405.

7. Cacheaux LP, Ivens S, David Y, Lakhter AJ, Bar-Klein G, Shapira M, Heinemann U, Friedman A, Kaufer D. Transcriptome profiling reveals TGF-beta signaling involvement in epileptogenesis. J Neurosci. 2009 Jul 15;29(28):8927-35. doi: 10.1523/JNEUROSCI.0430-09.2009. PMID: 19605630; PMCID: PMC2875073.

8. Cao S, Liu J, Song L, Ma X. The protooncogene c-Maf is an essential transcription factor for IL-10 gene expression in microglias. J Immunol. 2005 Mar 15;174(6):3484-92. doi: 10.4049/jimmunol.174.6.3484. PMID: 15749884; PMCID: PMC2955976.

9. Chen X, Zhang J, Song Y, Yang P, Yang Y, Huang Z, Wang K. Deficiency of anti-inflammatory cytokine IL-4 leads to neural hyperexcitability and aggravates cerebral ischemia-reperfusion injury. Acta Pharm Sin B. 2020 Sep;10(9):1634-1645. doi: 10.1016/j.apsb.2020.05.002. Epub 2020 May 20. PMID: 33088684; PMCID: PMC7564329.

10. Cherry JD, Olschowka JA, O'Banion MK. Neuroinflammation and M2 microglia: the good, the bad, and the inflamed. J Neuroinflammation. 2014 Jun 3;11:98. doi: 10.1186/1742-2094-11-98. PMID: 24889886; PMCID: PMC4060849.

11. Chong SA, Balosso S, Vandenplas C, Szczesny G, Hanon E, Claes K, Van Damme X, Danis B, Van Eyll J, Wolff C, Vezzani A, Kaminski RM, Niespodziany I. Intrinsic Inflammation Is a Potential AntiEpileptogenic Target in the Organotypic Hippocampal Slice Model. Neurotherapeutics. 2018 Apr;15(2):470-488. doi: 10.1007/s13311-018-0607-6. PMID: 29464573; PMCID: PMC5935638.

12. Clausen F, Marklund N, Hillered L. Acute Inflammatory Biomarker Responses to Diffuse Traumatic Brain Injury in the Rat Monitored by a Novel Microdialysis Technique. J Neurotrauma. 2019 Jan 15;36(2):201-211. doi: 10.1089/neu.2018.5636. Epub 2018 Aug 13. PMID: 29790398.

13. Conlon PJ, Tyler S, Grabstein KH, Morrissey P. Interleukin-4 (B-cell stimulatory factor-1) augments the in vivo generation of cytotoxic cells in immunosuppressed animals. Biotechnol Ther. 19891990;1(1):31-41. PMID: 2562642.

14. Cruz-Haces M, Tang J, Acosta G, Fernandez J, Shi R. Pathological correlations between traumatic brain injury and chronic neurodegenerative diseases. Transl Neurodegener. 2017 Jul 11;6:20. doi: 10.1186/s40035-017-0088-2. PMID: 28702179; PMCID: PMC5504572.

15. Dewan MC, Rattani A, Gupta S, Baticulon RE, Hung YC, Punchak M, Agrawal A, Adeleye AO, Shrime MG, Rubiano AM, Rosenfeld JV, Park KB. Estimating the global incidence of traumatic brain injury. J Neurosurg. 2018 Apr 1:1-18. doi: 10.3171/2017.10.JNS17352. Epub ahead of print. PMID: 29701556. 
16. Enam SF, Kader SR, Bodkin N, Lyon JG, Calhoun M, Azrak C, Tiwari PM, Vanover D, Wang H, Santangelo PJ, Bellamkonda RV. Evaluation of M2-like macrophage enrichment after diffuse traumatic brain injury through transient interleukin-4 expression from engineered mesenchymal stromal cells. J Neuroinflammation. 2020 Jun 20;17(1):197. doi: 10.1186/s12974-020-01860-y. PMID: 32563258; PMCID: PMC7306141.

17. Eslami M, Ghanbari E, Sayyah M, Etemadi F, Choopani S, Soleimani M, Amiri Z, Hadjighassem M. Traumatic brain injury accelerates kindling epileptogenesis in rats. Neurol Res. 2016 Mar;38(3):26974. doi: 10.1179/1743132815Y.0000000086. Epub 2016 Apr 19. PMID: 26315855.

18. Eslami M, Sayyah M, Soleimani M, Alizadeh L, Hadjighassem M. Lipopolysaccharide preconditioning prevents acceleration of kindling epileptogenesis induced by traumatic brain injury. J Neuroimmunol. 2015 Dec 15;289:143-51. doi: 10.1016/j.jneuroim.2015.11.003. Epub 2015 Nov 4. PMID: 26616884.

19. Francos-Quijorna I, Amo-Aparicio J, Martinez-Muriana A, López-Vales R. IL-4 drives microglia and macrophages toward a phenotype conducive for tissue repair and functional recovery after spinal cord injury. Glia. 2016 Dec;64(12):2079-2092. doi: 10.1002/glia.23041. Epub 2016 Jul 29. PMID: 27470986.

20. Girard S, Brough D, Lopez-Castejon G, Giles J, Rothwell NJ, Allan SM. Microglia and macrophages differentially modulate cell death after brain injury caused by oxygen-glucose deprivation in organotypic brain slices. Glia. 2013 May;61(5):813-24. doi: 10.1002/glia.22478. Epub 2013 Feb 13. PMID: 23404620; PMCID: PMC3644876.

21. Godukhin OV, Levin SG, Parnyshkova EY. The effects of interleukin-10 on the development of epileptiform activity in the hippocampus induced by transient hypoxia, bicuculline, and electrical kindling. Neurosci Behav Physiol. 2009 Sep;39(7):625-31. doi: 10.1007/s11055-009-9187-6. Epub 2009 Jul 21. PMID: 19621265.

22. Hart PH, Cooper RL, Finlay-Jones JJ. IL-4 suppresses IL-1 beta, TNF-alpha and PGE2 production by human peritoneal macrophages. Immunology. 1991 Mar;72(3):344-9. PMID: 2026443; PMCID: PMC1384393.

23. Hart PH, Vitti GF, Burgess DR, Whitty GA, Piccoli DS, Hamilton JA. Potential antiinflammatory effects of interleukin 4: suppression of human monocyte tumor necrosis factor alpha, interleukin 1, and prostaglandin E2. Proc Natl Acad Sci U S A. 1989 May;86(10):3803-7. doi: 10.1073/pnas.86.10.3803. PMID: 2786204; PMCID: PMC287229.

24. Hesam S, Khoshkholgh-Sima B, Pourbadie HG, Babapour V, Zendedel M, Sayyah M. Monophosphoryl Lipid A and Pam3Cys Prevent the Increase in Seizure Susceptibility and Epileptogenesis in Rats Undergoing Traumatic Brain Injury. Neurochem Res. 2018 Oct;43(10):1978-1985. doi: 10.1007/s11064-018-2619-3. Epub 2018 Sep 1. PMID: 30173323.

25. Hirschberg DL, Schwartz M. Macrophage recruitment to acutely injured central nervous system is inhibited by a resident factor: a basis for an immune-brain barrier. J Neuroimmunol. 1995 Aug;61(1):89-96. doi: 10.1016/0165-5728(95)00087-i. PMID: 7560018. 
26. Hunt RF, Boychuk JA, Smith BN. Neural circuit mechanisms of post-traumatic epilepsy. Front Cell Neurosci. 2013 Jun 18;7:89. doi: 10.3389/fncel.2013.00089. PMID: 23785313; PMCID:

PMC3684786.

27. Ishizaki Y, Kira R, Fukuda M, Torisu H, Sakai Y, Sanefuji M, Yukaya N, Hara T. Interleukin-10 is associated with resistance to febrile seizures: genetic association and experimental animal studies. Epilepsia. 2009 Apr;50(4):761-7. doi: 10.1111/j.1528-1167.2008.01861.x. Epub 2008 Dec 4. PMID: 19055487.

28. Kambayashi T, Jacob CO, Strassmann G. IL-4 and IL-13 modulate IL-10 release in endotoxinstimulated murine peritoneal mononuclear phagocytes. Cell Immunol. 1996 Jul 10;171(1):153-8. doi: 10.1006/cimm.1996.0186. PMID: 8660851.

29. Kamm K, Vanderkolk W, Lawrence C, Jonker M, Davis AT. The effect of traumatic brain injury upon the concentration and expression of interleukin-1 beta and interleukin-10 in the rat. J Trauma. 2006 Jan;60(1):152-7. doi: 10.1097/01.ta.0000196345.81169.a1. PMID: 16456449.

30. Kotlarz D, Marquardt B, Barøy T, Lee WS, Konnikova L, Hollizeck S, Magg T, Lehle AS, Walz C, Borggraefe I, Hauck F, Bufler P, Conca R, Wall SM, Schumacher EM, Misceo D, Frengen E, Bentsen BS, Uhlig HH, Hopfner KP, Muise AM, Snapper SB, Strømme P, Klein C. Human TGF- $\beta 1$ deficiency causes severe inflammatory bowel disease and encephalopathy. Nat Genet. 2018 Mar;50(3):344-348. doi: 10.1038/s41588-018-0063-6. Epub 2018 Feb 26. PMID: 29483653; PMCID: PMC6309869.

31. Kumar A, Loane DJ. Neuroinflammation after traumatic brain injury: opportunities for therapeutic intervention. Brain Behav Immun. 2012 Nov;26(8):1191-201. doi: 10.1016/j.bbi.2012.06.008. Epub 2012 Jun 21. PMID: 22728326.

32. Laffer B, Bauer D, Wasmuth S, Busch M, Jalilvand TV, Thanos S, Meyer Zu Hörste G, Loser K, Langmann T, Heiligenhaus A, Kasper M. Loss of IL-10 Promotes Differentiation of Microglia to a M1 Phenotype. Front Cell Neurosci. 2019 Oct 9;13:430. doi: 10.3389/fncel.2019.00430. PMID: 31649508; PMCID: PMC6794388.

33. Lagarde S, Villeneuve N, Trébuchon A, Kaphan E, Lepine A, McGonigal A, Roubertie A, Barthez MA, Trommsdorff V, Lefranc J, Wehbi S, des Portes V, Laguitton V, Quartier P, Scavarda D, Giusiano B, Milh M, Bulteau C, Bartolomei F. Anti-tumor necrosis factor alpha therapy (adalimumab) in Rasmussen's encephalitis: An open pilot study. Epilepsia. 2016 Jun;57(6):956-66. doi: 10.1111/epi.13387. Epub 2016 Apr 22. PMID: 27106864.

34. Lagraoui M, Latoche JR, Cartwright NG, Sukumar G, Dalgard CL, Schaefer BC. Controlled cortical impact and craniotomy induce strikingly similar profiles of inflammatory gene expression, but with distinct kinetics. Front Neurol. 2012 Oct 31;3:155. doi: 10.3389/fneur.2012.00155. PMID: 23118733; PMCID: PMC3484408.

35. Latta CH, Sudduth TL, Weekman EM, Brothers HM, Abner EL, Popa GJ, Mendenhall MD, GonzalezOregon F, Braun K, Wilcock DM. Determining the role of IL-4 induced neuroinflammation in microglial activity and amyloid- $\beta$ using BV2 microglial cells and APP/PS1 transgenic mice. J 
Neuroinflammation. 2015 Mar 4;12:41. doi: 10.1186/s12974-015-0243-6. PMID: 25885682; PMCID: PMC4350455.

36. Leach MW, Snyder EA, Sinha DP, Rosenblum IY. Safety evaluation of recombinant human interleukin4. I. Preclinical studies. Clin Immunol Immunopathol. 1997 Apr;83(1):8-11. doi:

10.1006/clin.1997.4303. PMID: 9073526.

37. Lee SI, Jeong SR, Kang YM, Han DH, Jin BK, Namgung U, Kim BG. Endogenous expression of interleukin-4 regulates macrophage activation and confines cavity formation after traumatic spinal cord injury. J Neurosci Res. 2010 Aug 15;88(11):2409-19. doi: 10.1002/jnr.22411. PMID: 20623539.

38. Levin SG, Godukhin OV. Protective effects of interleukin-10 on the development of epileptiform activity evoked by transient episodes of hypoxia in rat hippocampal slices. Neurosci Behav Physiol. 2007 Jun;37(5):467-70. doi: 10.1007/s11055-007-0036-1. PMID: 17505796.

39. Levings MK, Schrader JW. IL-4 inhibits the production of TNF-alpha and IL-12 by STAT6-dependent and -independent mechanisms. J Immunol. 1999 May 1;162(9):5224-9. PMID: 10227996.

40. Li HL, Kostulas N, Huang YM, Xiao BG, van der Meide P, Kostulas V, Giedraitas V, Link H. IL-17 and IFN-gamma mRNA expression is increased in the brain and systemically after permanent middle cerebral artery occlusion in the rat. J Neuroimmunol. 2001 May 1;116(1):5-14. doi: 10.1016/s01655728(01)00264-8. PMID: 11311324.

41. Li T, Zhai X, Jiang J, Song X, Han W, Ma J, Xie L, Cheng L, Chen H, Jiang L. Intraperitoneal injection of IL-4/IFN-y modulates the proportions of microglial phenotypes and improves epilepsy outcomes in a pilocarpine model of acquired epilepsy. Brain Res. 2017 Feb 15;1657:120-129. doi:

10.1016/j.brainres.2016.12.006. Epub 2016 Dec 10. PMID: 27956120.

42. Lima R, Monteiro S, Lopes JP, Barradas P, Vasconcelos NL, Gomes ED, Assunção-Silva RC, Teixeira FG, Morais M, Sousa N, Salgado AJ, Silva NA. Systemic Interleukin-4 Administration after Spinal Cord Injury Modulates Inflammation and Promotes Neuroprotection. Pharmaceuticals (Basel). 2017 Oct 24;10(4):83. doi: 10.3390/ph10040083. PMID: 29064422; PMCID: PMC5748640.

43. Liszczak TM, Hedley-Whyte ET, Adams JF, Han DH, Kolluri VS, Vacanti FX, Heros RC, Zervas NT. Limitations of tetrazolium salts in delineating infarcted brain. Acta Neuropathol. 1984;65(2):150-7. doi: $10.1007 / B F 00690469$.

44. Liu X, Liu J, Zhao S, Zhang H, Cai W, Cai M, Ji X, Leak RK, Gao Y, Chen J, Hu X. Interleukin-4 Is Essential for Microglia/Macrophage M2 Polarization and Long-Term Recovery After Cerebral Ischemia. Stroke. 2016 Feb;47(2):498-504. doi: 10.1161/STROKEAHA.115.012079. Epub 2016 Jan 5. PMID: 26732561; PMCID: PMC4729613.

45. Lively S, Schlichter LC. Microglia Responses to Pro-inflammatory Stimuli (LPS, IFNY+TNFa) and Reprogramming by Resolving Cytokines (IL-4, IL-10). Front Cell Neurosci. 2018 Jul 24;12:215. doi: 10.3389/fncel.2018.00215. PMID: 30087595; PMCID: PMC6066613.

46. Mantovani A, Biswas SK, Galdiero MR, Sica A, Locati M. Microglia plasticity and polarization in tissue repair and remodelling. J Pathol. 2013 Jan;229(2):176-85. doi: 10.1002/path.4133. Epub 2012 Nov 29. PMID: 23096265. 
47. Meng F, Yao L. The role of inflammation in epileptogenesis. Acta Epileptologica 2020; 2, 15. doi: 10.1186/s42494-020-00024-y.

48. Mitchell RE, Hassan M, Burton BR, Britton G, Hill EV, Verhagen J, Wraith DC. IL-4 enhances IL-10 production in Th1 cells: implications for Th1 and Th2 regulation. Sci Rep. 2017 Sep 12;7(1):11315. doi: 10.1038/s41598-017-11803-y. PMID: 28900244; PMCID: PMC5595963.

49. Mukherjee S, Arisi GM, Mims K, Hollingsworth G, O'Neil K, Shapiro LA. Neuroinflammatory mechanisms of post-traumatic epilepsy. J Neuroinflammation. 2020 Jun 17;17(1):193. doi: 10.1186/s12974-020-01854-w. PMID: 32552898; PMCID: PMC7301453.

50. Mukherjee S, Chen LY, Papadimos TJ, Huang S, Zuraw BL, Pan ZK. Lipopolysaccharide-driven Th2 cytokine production in macrophages is regulated by both MyD88 and TRAM. J Biol Chem. 2009 Oct 23;284(43):29391-8. doi: 10.1074/jbc.M109.005272. Epub 2009 Jul 28. PMID: 19638630; PMCID: PMC2785571.

51. Orecchioni M, Ghosheh Y, Pramod AB, Ley K. Macrophage Polarization: Different Gene Signatures in M1(LPS+) vs. Classically and M2(LPS-) vs. Alternatively Activated Macrophages. Front Immunol. 2019 May 24;10:1084. doi: 10.3389/fimmu.2019.01084. Erratum in: Front Immunol. 2020 Feb 25;11:234. PMID: 31178859; PMCID: PMC6543837.

52. Patel DC, Wallis G, Dahle EJ, McElroy PB, Thomson KE, Tesi RJ, Szymkowski DE, West PJ, Smeal RM, Patel M, Fujinami RS, White HS, Wilcox KS. Hippocampal TNFa Signaling Contributes to Seizure Generation in an Infection-Induced Mouse Model of Limbic Epilepsy. eNeuro. 2017 May 9;4(2):ENEURO.0105-17.2017. doi: 10.1523/ENEURO.0105-17.2017. PMID: 28497109; PMCID: PMC5422919.

53. Paxinos G, Watson C. The rat brain in stereotaxic coordinates. 2007. Elsevier, Academic press, San Diego.

54. Pepe G, Calderazzi G, De Maglie M, Villa AM, Vegeto E. Heterogeneous induction of microglia M2a phenotype by central administration of interleukin-4. J Neuroinflammation. 2014 Dec 31;11:211. doi: 10.1186/s12974-014-0211-6. PMID: 25551794; PMCID: PMC4302702.

55. Prehn JH, Backhauss C, Krieglstein J. Transforming growth factor-beta 1 prevents glutamate neurotoxicity in rat neocortical cultures and protects mouse neocortex from ischemic injury in vivo. $J$ Cereb Blood Flow Metab. 1993 May;13(3):521-5. doi: 10.1038/jcbfm.1993.67. PMID: 8097519. Pu, H., Zheng, X., Jiang, X., Mu, H., Xu, F., Zhu, W., Ye, Q., Jizhang, Y., Hitchens, T.K., Shi, Y., Hu, X., Leak, R.K., Dixon, C.E., Bennett, M.V.I., Chen, J., 2020. Interleukin-4 improves white matter integrity and functional recovery after murine traumatic brain injury via oligodendroglial PPARY. J. Cereb. Blood Flow Metab. 271678X20941393. https://doi.org/10.1177/0271678X20941393.

56. Racine RJ. Modification of seizure activity by electrical stimulation. II. Motor seizure. Electroencephalogr Clin Neurophysiol. 1972 Mar;32(3):281-94. doi: 10.1016/0013-4694(72)90177-0. PMID: 4110397.

57. Rana A, Musto AE. The role of inflammation in the development of epilepsy. J Neuroinflammation. 2018 May 15;15(1):144. doi: 10.1186/s12974-018-1192-7. PMID: 29764485; PMCID: PMC5952578. 
58. Ratthé C, Ennaciri J, Garcês Gonçalves DM, Chiasson S, Girard D. Interleukin (IL)-4 induces leukocyte infiltration in vivo by an indirect mechanism. Mediators Inflamm. 2009;2009:193970. doi:

10.1155/2009/193970. Epub 2009 Sep 10. PMID: 19753321; PMCID: PMC2742652.

59. Reinhart R, Kaufmann T. IL-4 enhances survival of in vitro-differentiated mouse basophils through transcription-independent signaling downstream of PI3K. Cell Death Dis. 2018 Jun 18;9(7):713. doi: 10.1038/s41419-018-0754-z. PMID: 29915306; PMCID: PMC6006176.

60. Riazi K, Galic MA, Kuzmiski JB, Ho W, Sharkey KA, Pittman QJ. Microglial activation and TNFalpha production mediate altered CNS excitability following peripheral inflammation. Proc Natl Acad Sci U S A. 2008 Nov 4;105(44):17151-6. doi: 10.1073/pnas.0806682105. Epub 2008 Oct 27. PMID: 18955701; PMCID: PMC2579393.

61. Rossi C, Cusimano M, Zambito M, Finardi A, Capotondo A, Garcia-Manteiga JM, Comi G, Furlan R, Martino G, Muzio L. Interleukin 4 modulates microglia homeostasis and attenuates the early slowly progressive phase of amyotrophic lateral sclerosis. Cell Death Dis. 2018 Feb 14;9(2):250. doi: 10.1038/s41419-018-0288-4. PMID: 29445154; PMCID: PMC5833860.

62. Salmon-Ehr V, Ramont L, Godeau G, Birembaut P, Guenounou M, Bernard P, Maquart FX. Implication of interleukin-4 in wound healing. Lab Invest. 2000 Aug;80(8):1337-43. doi:

10.1038/labinvest.3780141. PMID: 10950124.

63. Sharma S, Tiarks G, Haight J, Bassuk AG. Neuropathophysiological Mechanisms and Treatment Strategies for Post-traumatic Epilepsy. Front Mol Neurosci. 2021 Feb 23;14:612073. doi: 10.3389/fnmol.2021.612073. PMID: 33708071; PMCID: PMC7940684.

64. Sun L, Shan W, Yang H, Liu R, Wu J, Wang Q. The Role of Neuroinflammation in Post-traumatic Epilepsy. Front Neurol. 2021 May 28;12:646152. doi: 10.3389/fneur.2021.646152. PMID: 34122298; PMCID: PMC8194282.

65. Taupin V, Toulmond S, Serrano A, Benavides J, Zavala F. Increase in IL-6, IL-1 and TNF levels in rat brain following traumatic lesion. Influence of pre- and post-traumatic treatment with Ro5 4864, a peripheral-type ( $p$ site) benzodiazepine ligand. J Neuroimmunol. 1993 Feb;42(2):177-85. doi: 10.1016/0165-5728(93)90008-m. PMID: 8429103.

66. Turtzo LC, Lescher J, Janes L, Dean DD, Budde MD, Frank JA. Macrophagic and microglial responses after focal traumatic brain injury in the female rat. J Neuroinflammation. 2014 Apr 24;11:82. doi: 10.1186/1742-2094-11-82. PMID: 24761998; PMCID: PMC4022366.

67. Van Kampen C, Gauldie J, Collins SM. Proinflammatory properties of IL-4 in the intestinal microenvironment. Am J Physiol Gastrointest Liver Physiol. 2005 Jan;288(1):G111-7. doi: 10.1152/ajpgi.00014.2004. PMID: 15591585.

68. Ven $\varnothing$ MT, Reschke CR, Morris G, Connolly NMC, Su J, Yan Y, Engel T, Jimenez-Mateos EM, Harder LM, Pultz D, Haunsberger SJ, Pal A, Heller JP, Campbell A, Langa E, Brennan GP, Conboy K, Richardson A, Norwood BA, Costard LS, Neubert V, Del Gallo F, Salvetti B, Vangoor VR, Sanz-Rodriguez A, Muilu J, Fabene PF, Pasterkamp RJ, Prehn JHM, Schorge S, Andersen JS, Rosenow F, Bauer S, Kjems J, Henshall DC. A systems approach delivers a functional microRNA catalog and expanded targets for 
seizure suppression in temporal lobe epilepsy. Proc Natl Acad Sci U S A. 2020 Jul 7;117(27):1597715988. doi: 10.1073/pnas.1919313117. Epub 2020 Jun 24. PMID: 32581127; PMCID: PMC7355001.

69. Vokes EE, Figlin R, Hochster H, Lotze M, Rybak ME. A phase II study of recombinant human interleukin-4 for advanced or recurrent non-small cell lung cancer. Cancer J Sci Am. 1998 JanFeb;4(1):46-51. PMID: 9467046.

70. Wang F, Wang X, Shapiro LA, Cotrina ML, Liu W, Wang EW, Gu S, Wang W, He X, Nedergaard M, Huang JH. NKCC1 up-regulation contributes to early post-traumatic seizures and increased posttraumatic seizure susceptibility. Brain Struct Funct. 2017 Apr;222(3):1543-1556. doi: 10.1007/s00429-016-1292-z. Epub 2016 Sep 1. PMID: 27586142; PMCID: PMC5368191.

71. Webster KM, Sun M, Crack P, O'Brien TJ, Shultz SR, Semple BD. Inflammation in epileptogenesis after traumatic brain injury. J Neuroinflammation. 2017 Jan 13;14(1):10. doi: 10.1186/s12974-016-07861. PMID: 28086980; PMCID: PMC5237206.

72. Woodcock T, Morganti-Kossmann MC. The role of markers of inflammation in traumatic brain injury. Front Neurol. 2013 Mar 4;4:18. doi: 10.3389/fneur.2013.00018. PMID: 23459929; PMCID: PMC3586682.

73. Woodward EA, Prêle CM, Nicholson SE, Kolesnik TB, Hart PH. The anti-inflammatory effects of interleukin-4 are not mediated by suppressor of cytokine signalling-1 (SOCS1). Immunology. 2010 Sep;131(1):118-27. doi: 10.1111/j.1365-2567.2010.03281.x. Epub 2010 Apr 6. PMID: 20406299; PMCID: PMC2966764.

74. Wyss-Coray T, Feng L, Masliah E, Ruppe MD, Lee HS, Toggas SM, Rockenstein EM, Mucke L. Increased central nervous system production of extracellular matrix components and development of hydrocephalus in transgenic mice overexpressing transforming growth factor-beta 1 . Am J Pathol. 1995 Jul;147(1):53-67. PMID: 7604885; PMCID: PMC1869892.

75. Xiong Y, Mahmood A, Chopp M. Current understanding of neuroinflammation after traumatic brain injury and cell-based therapeutic opportunities. Chin J Traumatol. 2018 Jun;21(3):137-151. doi: 10.1016/j.cjtee.2018.02.003. Epub 2018 Apr 24. PMID: 29764704; PMCID: PMC6034172.

76. Xiong X, Barreto GE, Xu L, Ouyang YB, Xie X, Giffard RG. Increased brain injury and worsened neurological outcome in interleukin-4 knockout mice after transient focal cerebral ischemia. Stroke. 2011 Jul;42(7):2026-32. doi: 10.1161/STROKEAHA.110.593772. Epub 2011 May 19. PMID: $21597016 ;$ PMCID: PMC3128567.

77. Zamorano J, Wang HY, Wang LM, Pierce JH, Keegan AD. IL-4 protects cells from apoptosis via the insulin receptor substrate pathway and a second independent signaling pathway. J Immunol. 1996 Dec 1;157(11):4926-34. PMID: 8943397.

78. Zhang W, Zhang Y, He Y, Wang X, Fang Q. Lipopolysaccharide mediates time-dependent macrophage M1/M2 polarization through the Tim-3/Galectin-9 signalling pathway. Exp Cell Res. 2019 Mar 15;376(2):124-132. doi: 10.1016/j.yexcr.2019.02.007. Epub 2019 Feb 11. PMID: 30763585.

79. Zhao X, Wang H, Sun G, Zhang J, Edwards NJ, Aronowski J. Neuronal Interleukin-4 as a Modulator of Microglial Pathways and Ischemic Brain Damage. J Neurosci. 2015 Aug 12;35(32):11281-91. doi: 
10.1523/JNEUROSCI.1685-15.2015. PMID: 26269636; PMCID: PMC4532758.

80. Zhou X, Spittau B, Krieglstein K. TGF $\beta$ signalling plays an important role in IL4-induced alternative activation of microglia. J Neuroinflammation. 2012 Sep 4;9:210. doi: 10.1186/1742-2094-9-210. PMID: 22947253; PMCID: PMC3488564.

81. Yao Y, Xu XH, Jin L. Macrophage Polarization in Physiological and Pathological Pregnancy. Front Immunol. 2019 Apr 15;10:792. doi: 10.3389/fimmu.2019.00792. PMID: 31037072; PMCID: PMC6476302.

\section{Figures}


A

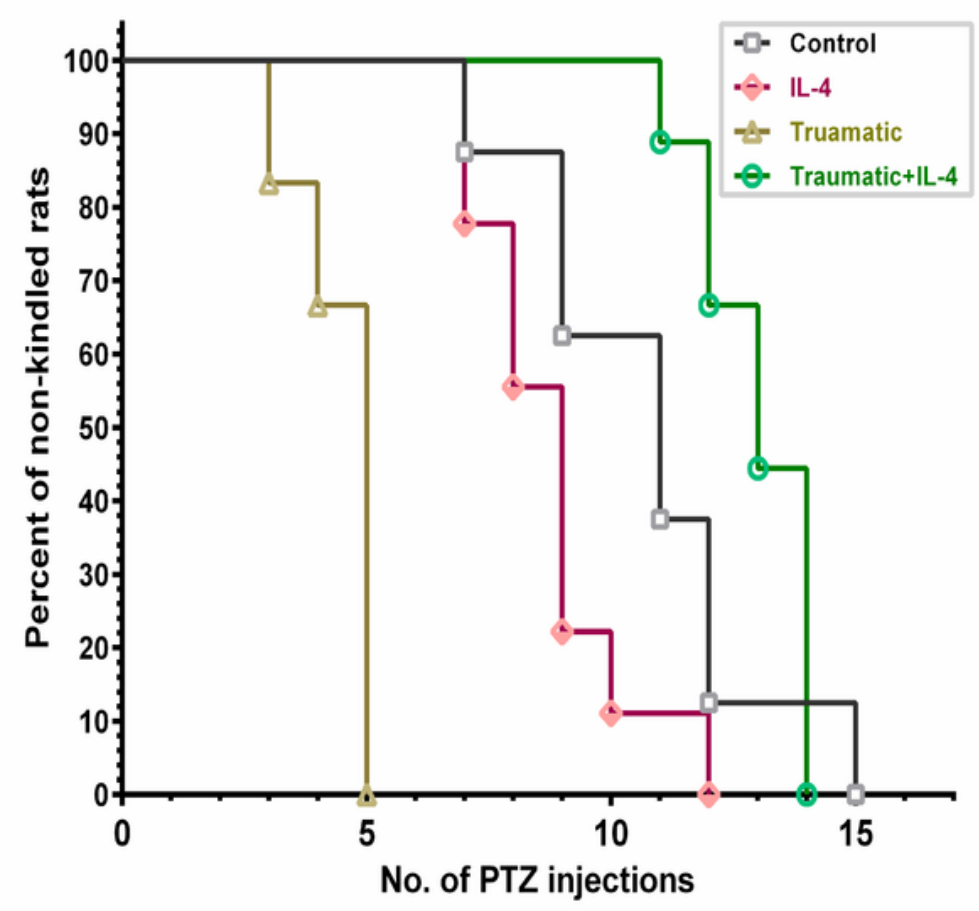

B

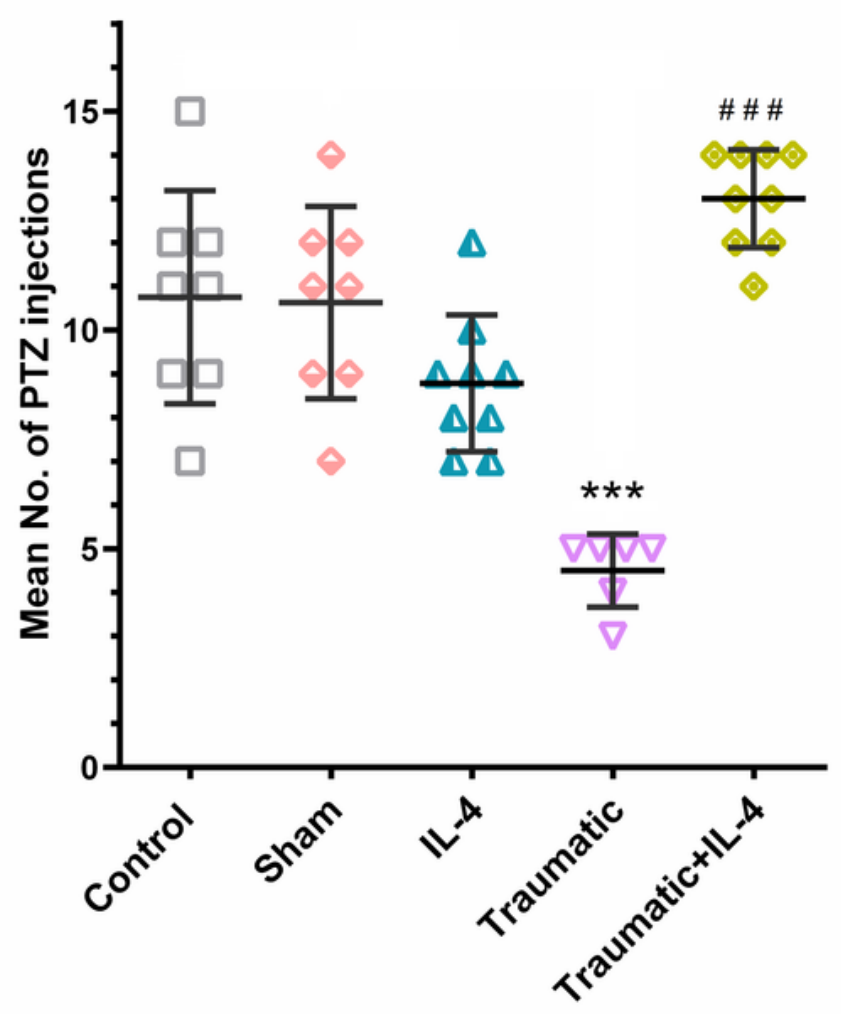

\section{Figure 1}

Effect of IL-4 on development of generalized seizures in traumatic rats. A: Kaplan-Meier survival analysis for development of PTZ kindling in traumatic rats. Traumatic rats became kindled significantly $(p<0.05$; Log-rank Mantel-Cox test) earlier than the sham-operated rats. IL-4 restored the accelerated rate of kindling in traumatic rats to control level. B: Number of PTZ injections needed for acquisition of generalized seizures. Each plot represents Mean \pm SEM. ***: $p<0.001$ compared with control and sham 
groups, \#\#\#: $p<0.001$ compared with trauma group (analyzed by one way ANOVA with Tukey's post-hoc multiple comparisons test).
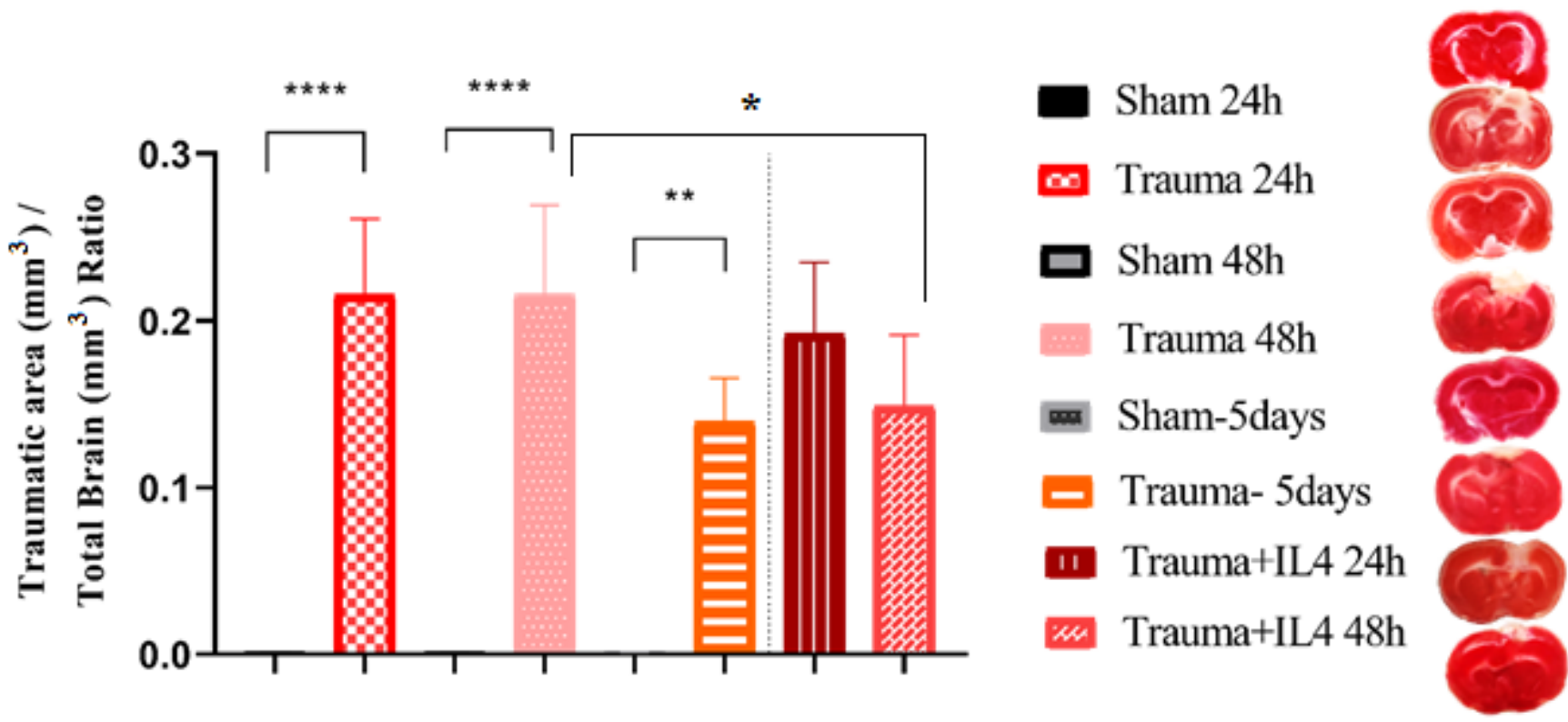

\section{Figure 2}

Effect of intracerebroventricular administration of interleukin 4 on size of temporoparietal cortical tissue injury induced by controlled cortical impact in rats. The viable tissue (red stained) was distinguished from the dead tissue (white unstained) by 2,3,5-Triphenyltetrazolium staining. Data are presented as mean \pm SEM. **: $p<0.01$, and $* \star \star *: p<0.0001$ compared to corresponding sham group (analyzed by one way ANOVA with Tukey's post-hoc multiple comparisons test). 


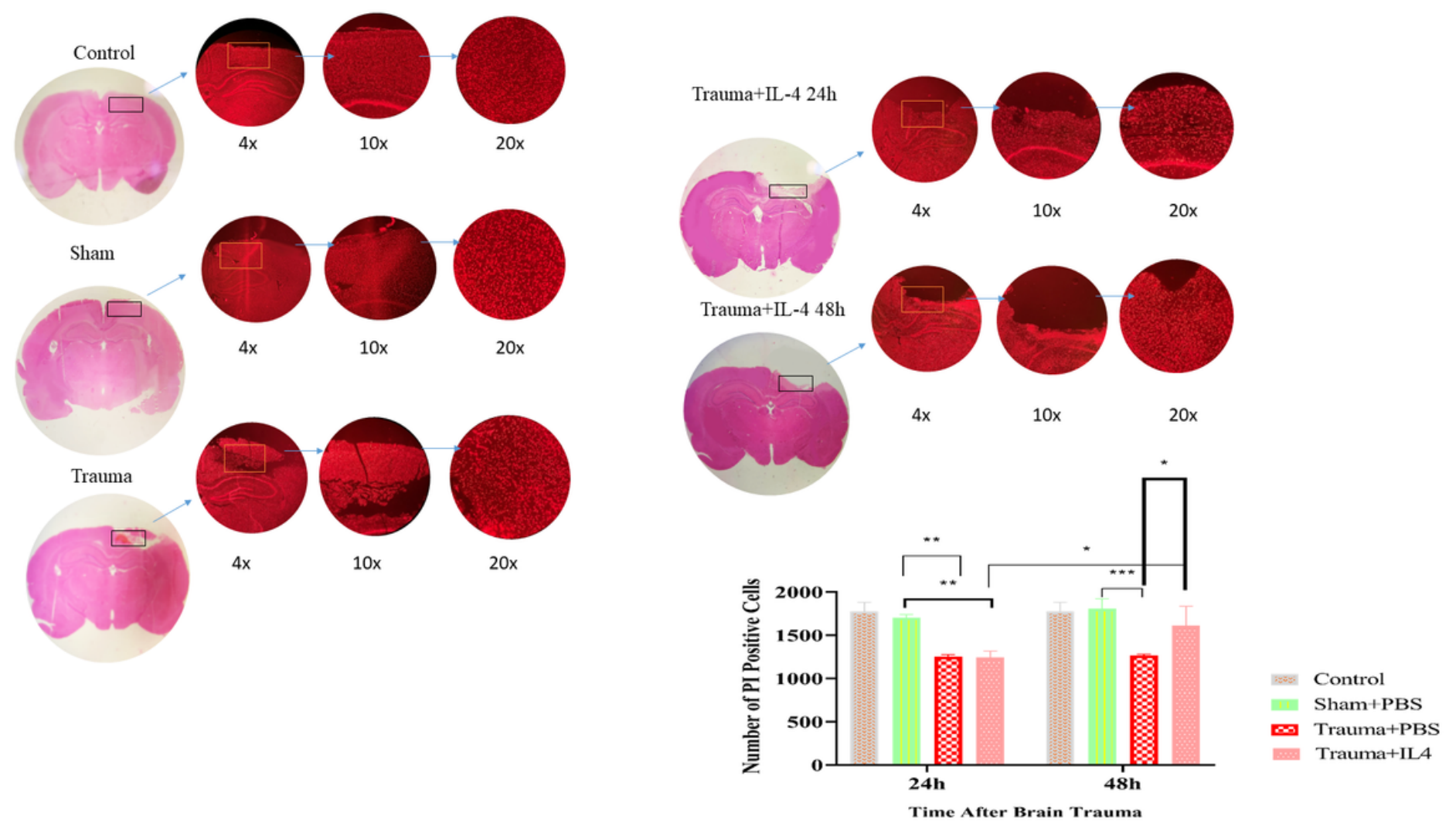

Figure 3

Effect of interleukin 4 on the cell viability in the traumatic brain region of rats. The number of propidium iodide (PI)-stained cells were counted in the traumatic area $(5 \mathrm{~mm}$ width, and $2.2 \mathrm{~mm}$ depth from cerebral cortex) of every 10 sections ( $8 \mu \mathrm{m}$ thickness of each section). Data are presented as mean \pm SEM number of PI-positive cells per section. *: $p<0.05, * *: p<0.01$, and ***: $p<0.001$ analyzed by two-way ANOVA with multiple comparisons test. 


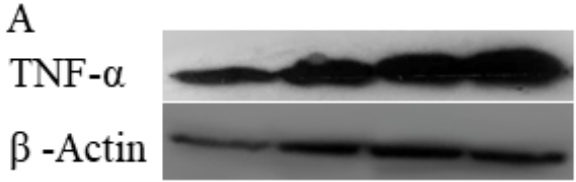

Sham-3h Sham-6h Trauma-3h Trauma- 6 h

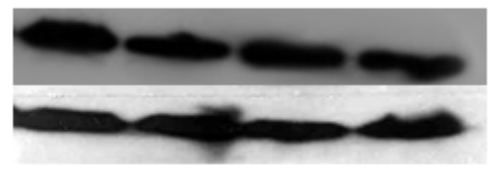

Sham-24h Trauma- $24 \mathrm{~h}$ Sham-5days Trauma-5days

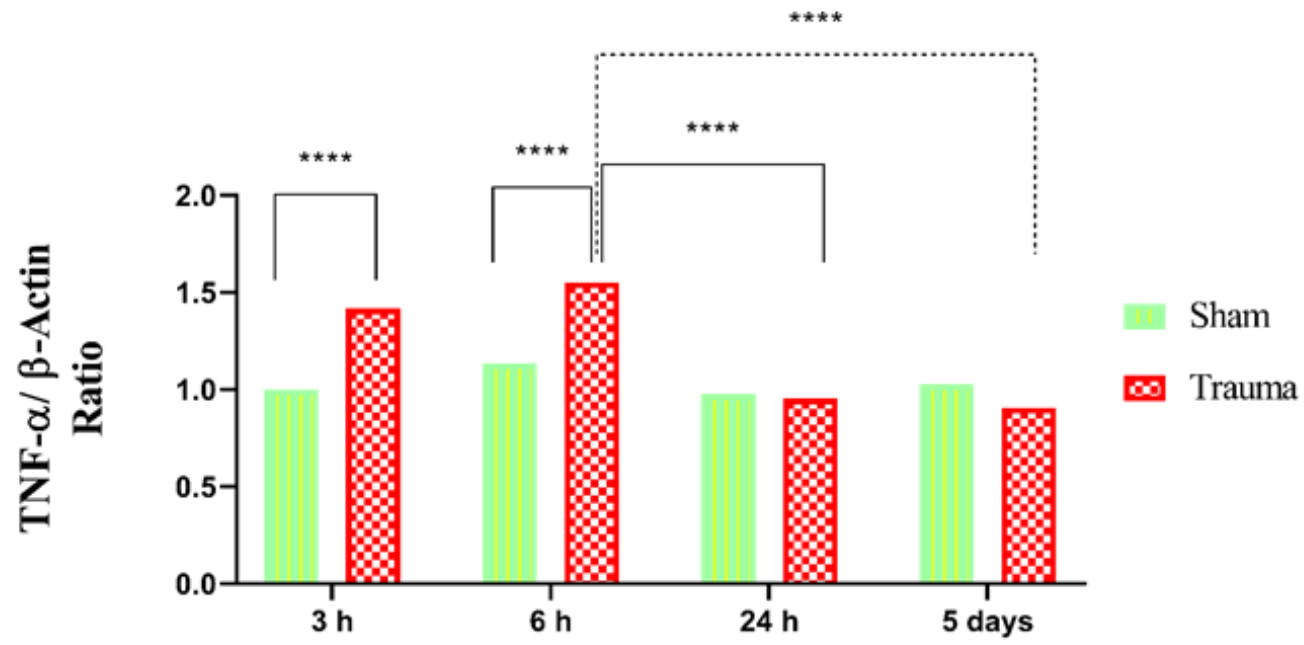

B

TNF- $\alpha$

$\beta$-Actin

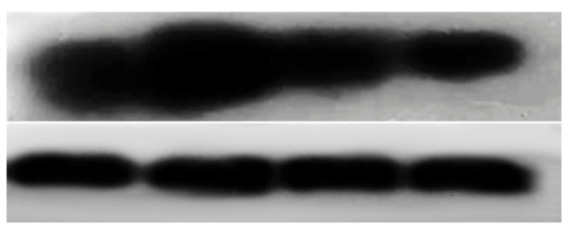

Sham-6h Trauma-6h Sham+IL4-6h Trauma + IL 4-6h

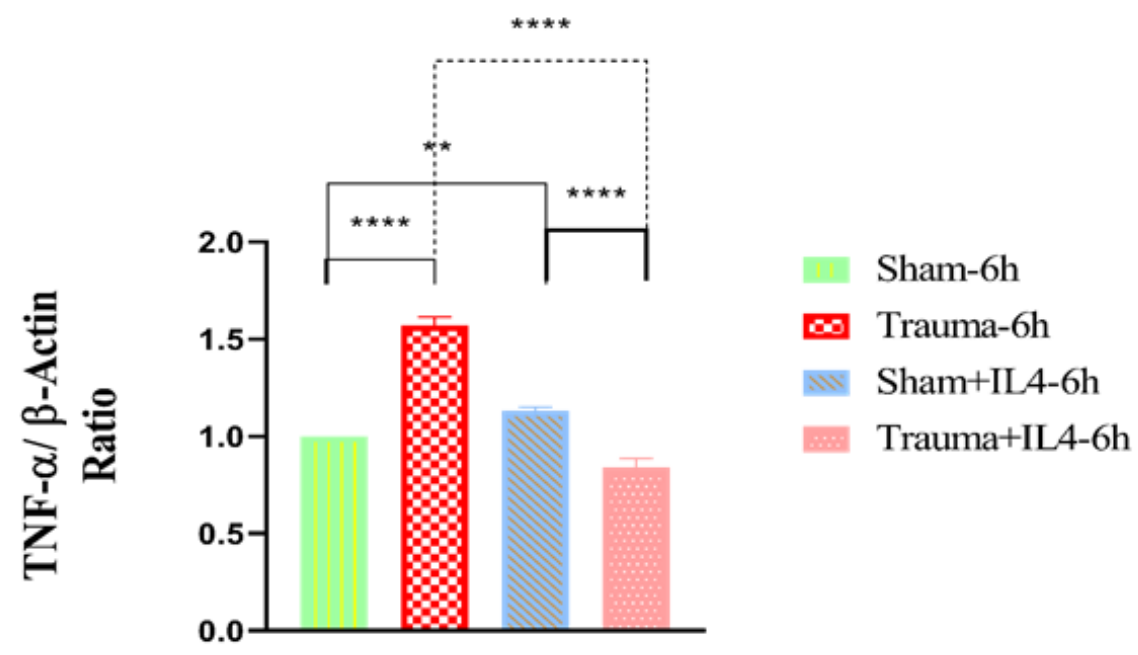

Figure 4

Effect of interleukin 4 on TNF-a up-regulation after traumatic brain injury in rats. A: Time course of TNF-a protein expression after Controlled Cortical Impact injury. B: Effect of IL-4 on TNF-a overexpression $6 \mathrm{~h}$ after traumatic brain injury. Upper part: The representative blots of brain TNF- $\alpha$ and $B$-actin (internal control) obtained by Western blot technique. Lower part: The mean ratio of TNF-a to ß-actin. *: $p<0.05$, 
$\star *: p<0.01, * \star *: p<0.001$, and $* \star \star *: p<0.0001$ analyzed by two-way ANOVA with multiple comparisons test.
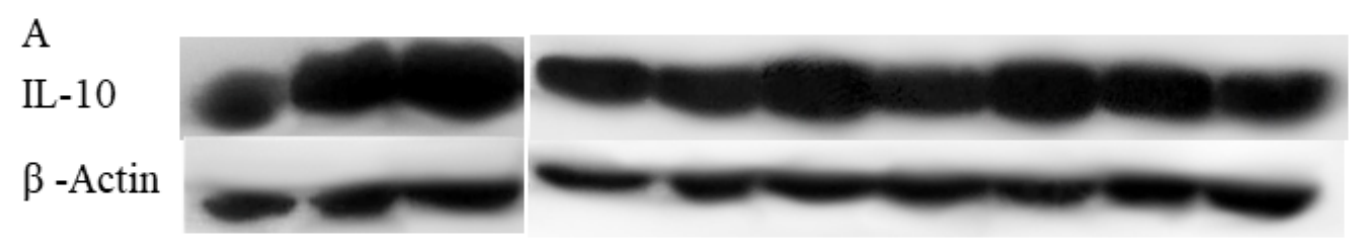

Control Sham-6h Trauma-6h Control Sham-12h Trauma-12 Sham-24h Trauma-24h Sham-48h Trauma-48h

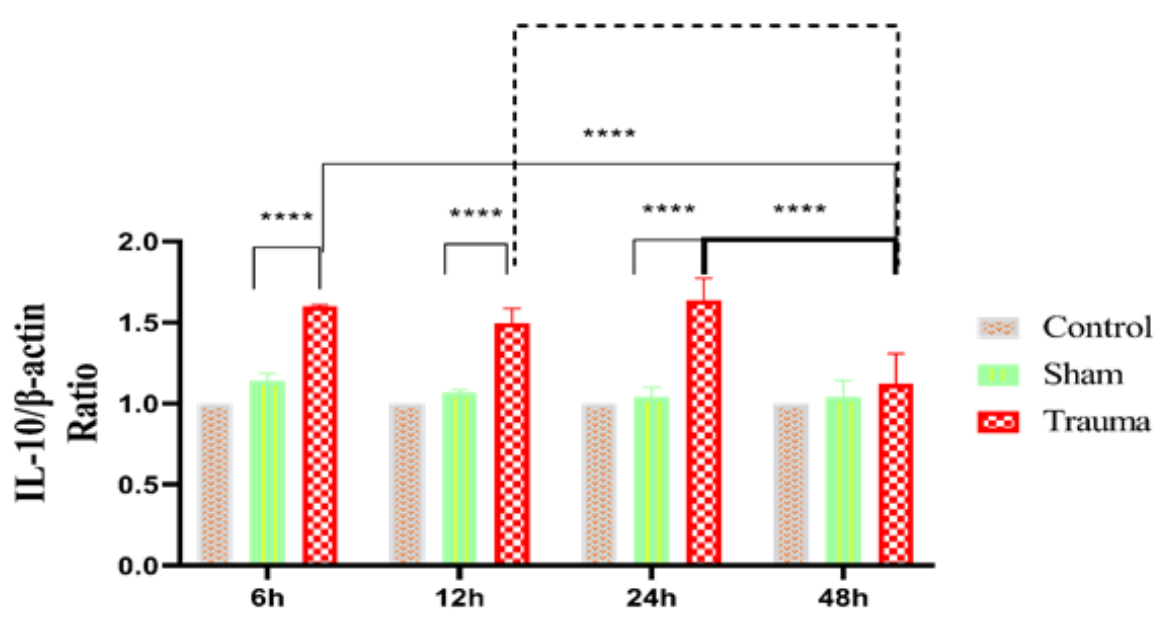

B

IL-10

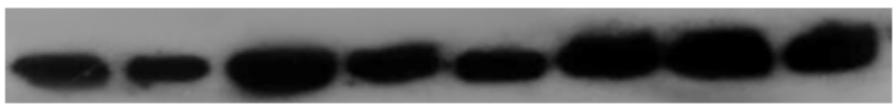

$\beta$-Actin
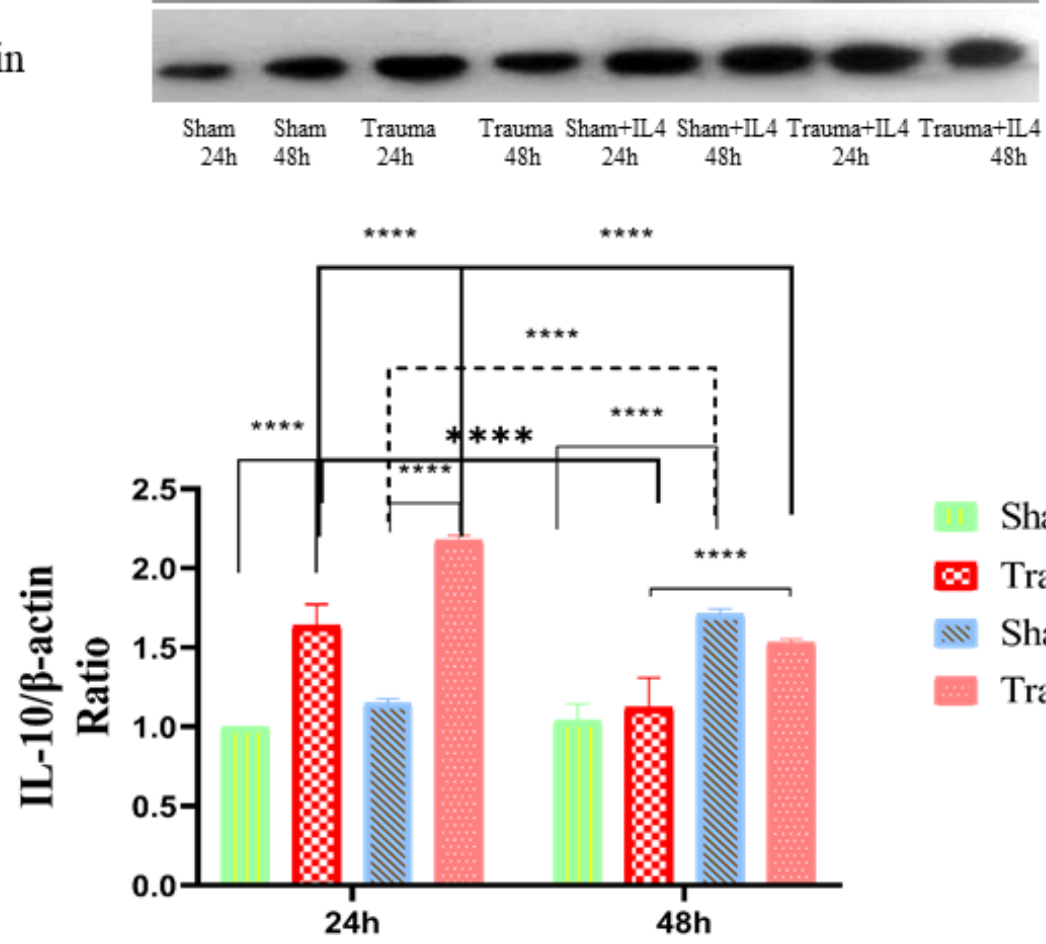

Sham

Trauma

Sham+IL4

Trauma+IL4

\section{Figure 5}

Effect of interleukin 4 on Interleukin 10 up-regulation after traumatic brain injury in rats. A: Time course of IL-10 protein expression after Controlled Cortical Impact injury. B: Effect of IL-4 on IL-10 overexpression 24 and $48 \mathrm{~h}$ after traumatic brain injury. Upper part: The representative blots of brain IL-10 and ß-actin 
(internal control) obtained by Western blot technique. Lower part: The mean ratio of IL-10 to ß-actin. *: $\mathrm{p}<$ $0.05, * *: p<0.01$, and $* * \star *: p<0.0001$ analyzed by two-way ANOVA with multiple comparisons test.

A

TGF- $\beta$

$\beta$-Actin

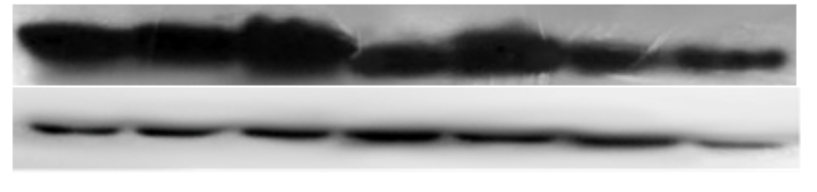

Control Sham-6h Trauma-6h Sham-24h Trauma-24h Sham-48h Trauma-48h

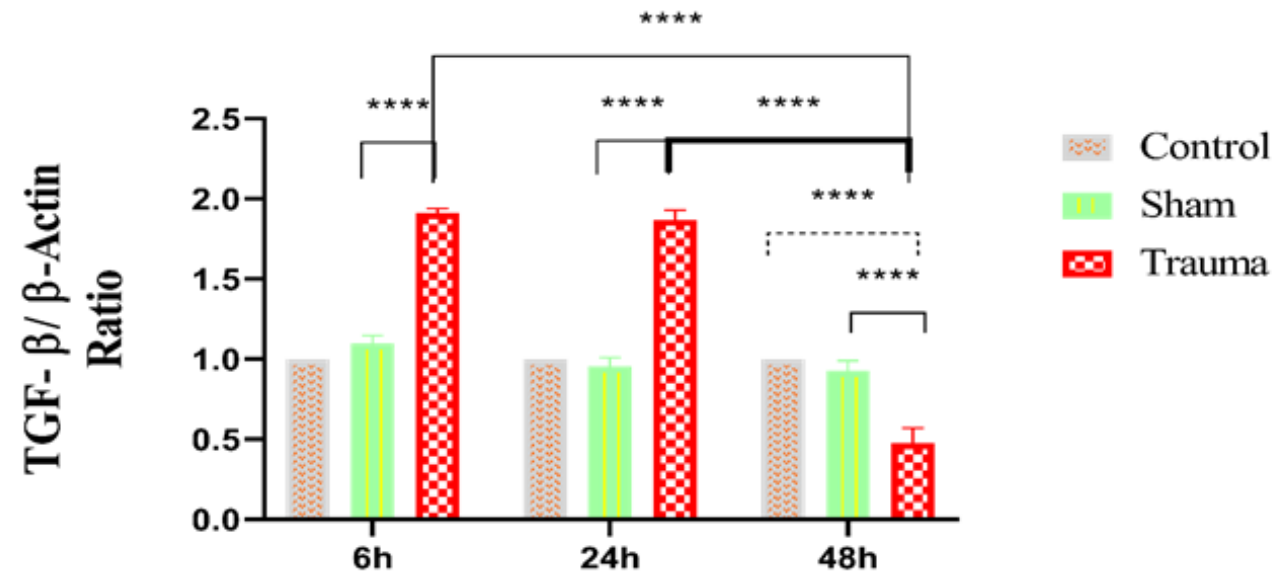

B

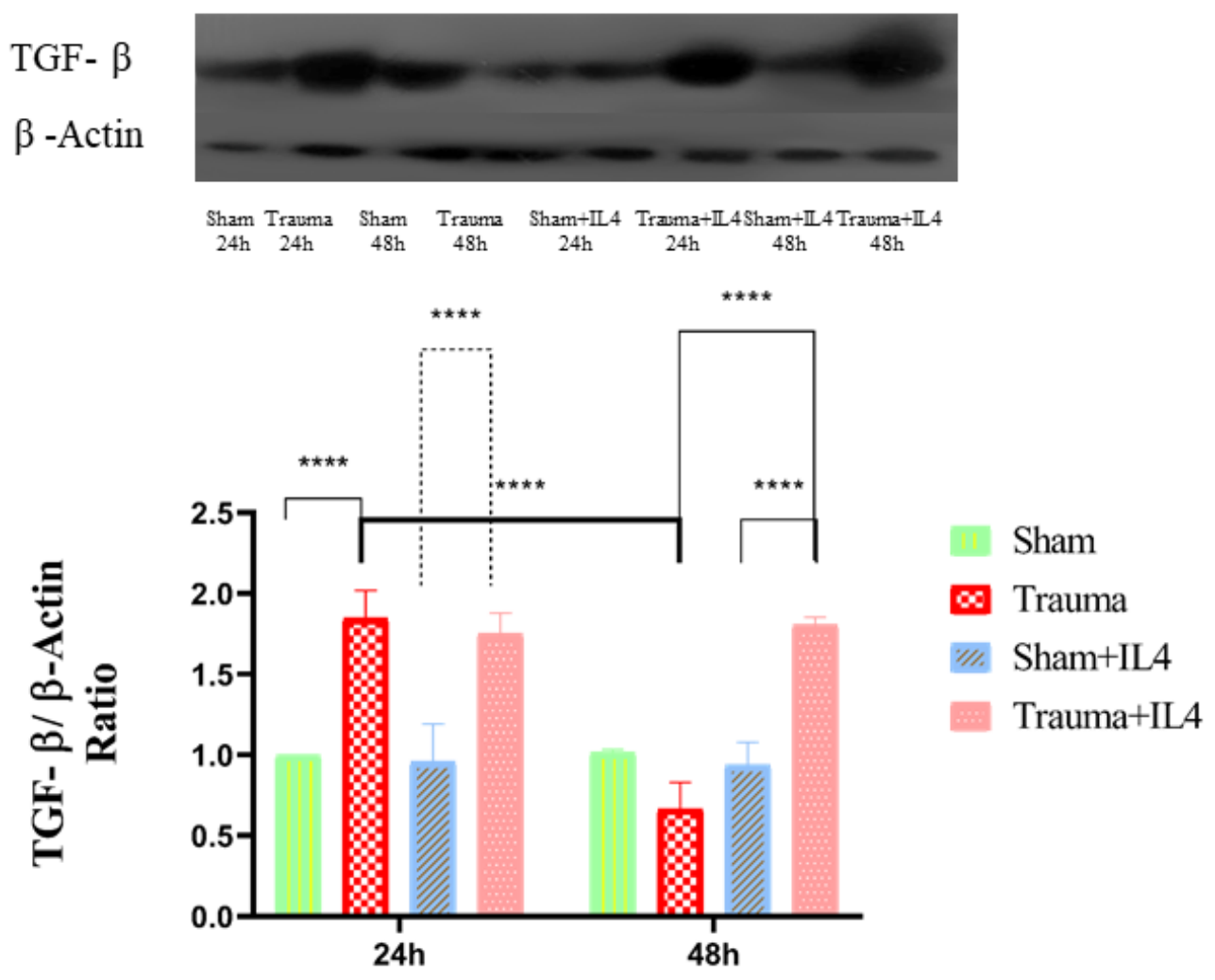

Figure 6

Effect of interleukin 4 on Transforming growth factor- $\beta$ expression after traumatic brain injury in rats. A: Time course of TGF- $\beta$ protein expression after Controlled Cortical Impact injury. B: Effect of IL- 4 on TGF- $\beta$ overexpression 24 and $48 \mathrm{~h}$ after traumatic brain injury. Upper part: The representative blots of brain TGF- 
$\beta$ and $B$-actin (internal control) obtained by Western blot technique. Lower part: The mean ratio of IL-10 to ß-actin. $* *: p<0.01, * \star *: p<0.001$, and $* \star * *: p<0.0001$ analyzed by two-way ANOVA with multiple comparisons test.

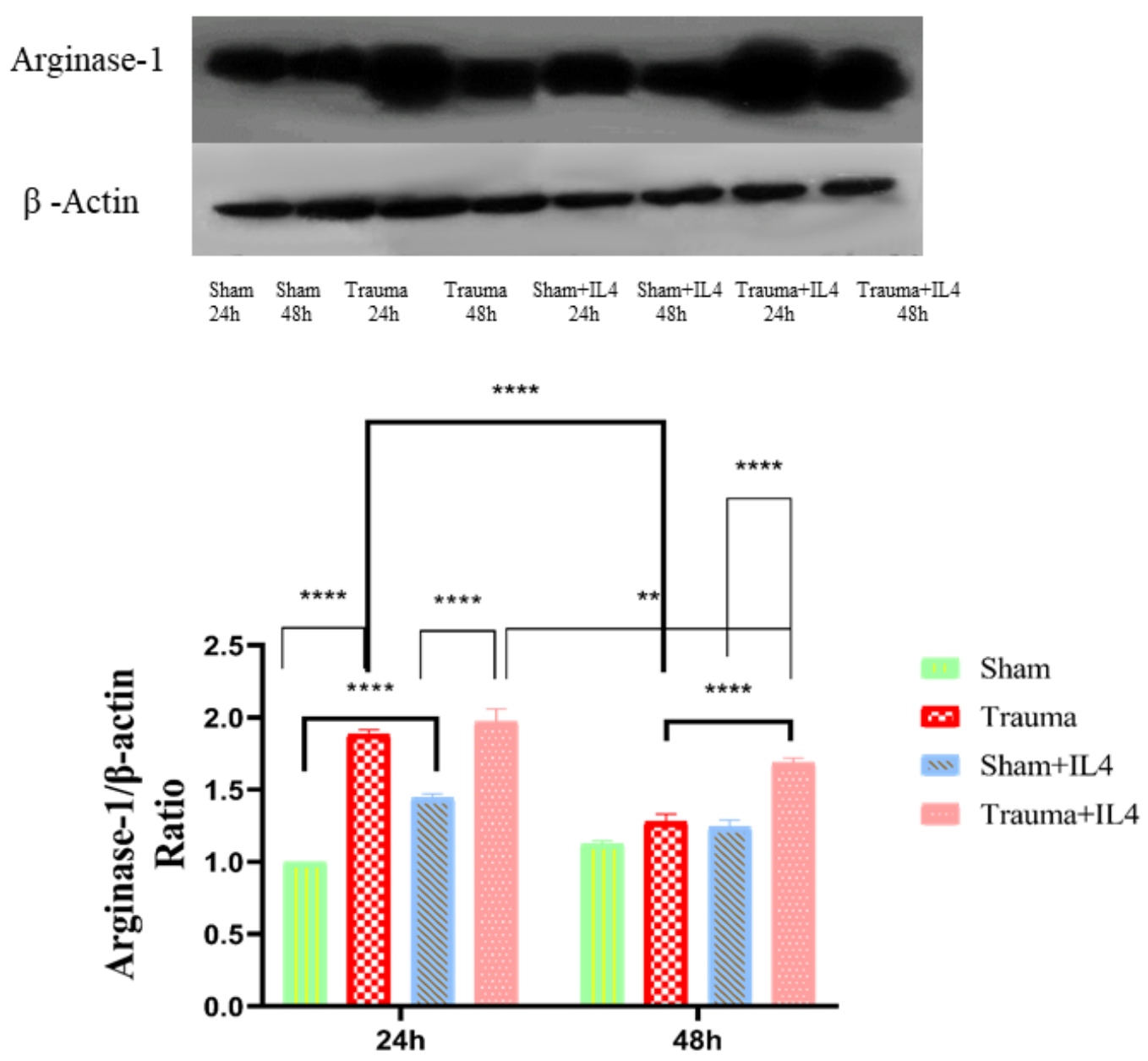

Figure 7

Effect of IL-4 on brain expression of arginase-1 in traumatic rats. Upper part: The representative Western blots of brain arginase-1and ß-actin (internal control) obtained 24 and $48 \mathrm{~h}$ after Controlled Cortical 
Impact injury. Lower part: The mean ratio of arginase-1 to ß-actin. $*$ : $p<0.05,{ }^{\star * \star}$ : $p<0.001$, and ***: $p<$ 0.0001 analyzed by two-way ANOVA with multiple comparisons test. 